\title{
Perception management of non-sewered sanitation systems towards scheduled faecal sludge emptying behaviour change intervention
}

Peter Emmanuel Cookey ${ }^{1 凶}$, Ziggy Kugedera ${ }^{2}$, Muhammed Alamgir ${ }^{3}$ \& Damir Brdjanovic ${ }^{1}$

This paper explores the influence of perception on behaviours associated with emptying of faecal sludge from non-sewered sanitation systems using findings from a study on the emptying behaviour of residents of Khulna city, Bangladesh. The purpose of the study was to highlight perception as a behaviour determinants as well as develop perception management strategies for the design, plan and implementation of effective behaviour change intervention programmes with a focus on 'scheduled emptying'. The study uses a mixed-method crosssectional approach to collect data through structured household questionnaire surveys, faceto-face key informant interviews, group interviews, and structured observations. The study revealed that the emptying behaviour of the community was reactive, untimely and unsafe and over half of the systems had never been emptied, which was traced to emptying perceptions that encouraged a laissez-faire attitude within households and the community. The study concluded by proposing a perception management model to achieve behaviour change towards scheduled emptying via perception change.

\footnotetext{
${ }^{1}$ Water Supply, Sanitation and Environmental Engineering Department, IHE Delft Institute for Water Education, Delft, The Netherlands. ${ }^{2}$ WASH Knowledge Management Department, UNICEF, Islamabad, Pakistan. ${ }^{3}$ Khulna University of Engineering and Technology (KUET), Khulna, Bangladesh.

凶email: cookeypeter@gmail.com
} 


\section{Introduction}

on-sewered sanitation (NSS) systems (or onsite sanitation systems [OSS]) are estimated to serve 2.8 billion people globally (Cairns-Smith et al., 2014; Peal et al., 2014; Strande et al., 2018), but the current reactive and emergency emptying practice of users/owners of these systems is unsafe and laden with risks of exposure to pathogenic organisms. To achieve timely and safe scheduled emptying will require interventions that address a change in the emptying behaviour of the community of users, but a clear understanding of their perception on the subject matter is necessary to facilitate a behaviour change. Scheduled emptying (desludging) that is regular, safe and preventive are conducted at intervals appropriate to local conditions with emphasis on sludge accumulation, as well as containment type and size. It also involves the use of approved mechanical/ motorised equipment (e.g., vacuum trucks) and trained manual emptiers with personal protective equipment (PPE) (e.g., Gulpers) (Parkinson and Quader, 2008; Mondal, 2018; Mondal et al., 2018; Kugedera, 2019). On the other hand, on-demand/emergency emptying is unsafe and occurs only when the system overflows or stops working (ISF-UTS and SNV, 2019; Mehta et al., 2019) or effluents are directly discharged into the environment while unsafe desludging is done manually by unskilled-workers with improvised tools and no personal protective equipment (PPE) could be fatal for the workers (Tyagi, 2017). The authors of this paper conducted a study of 80 households in Khulna Ward 9 (Bangladesh) to determine the prevailing emptying behaviour in the study area and the appropriate behaviour change strategies required. An unexpected pattern came up from the study, which implied that whatever emptying behaviour a person or group of persons adopted depended on inherent individual or group perceptions (Bargh and Ferguson, 2000). In essence, owners and/or users of OSS often based their emptying behaviours on their perceptions rather than on any scientific measures or regulatory directives and standards (Taylor, 1975).

The related health and safety risks of exposure to users and workers make it expedient to address how sanitation containment technologies (e.g., septic tank, aqua privies and pit latrines) are emptied because inappropriate collection and delivery of faecal sludge for proper treatment cause serious public and environmental health consequences (Eales, 2005; Kengne et al., 2011; Peal et al., 2014; Murungi and Pieter van Dijk, 2014; Strande et al., 2018). When desludging is irregular or delayed it affects the effective functioning of the sanitation containment system and then lead to overflow and spill over into the surrounding environment with poor quality effluents (ISF-UTS and SNV, 2019; Mehta et al., 2019). Worse still, these poor quality effluents most often end up in waterbodies, soil and urban spaces, which could negatively impact the health and environment of close communities (Peal et al., 2014; Strande et al., 2014; Appiah-Effah et al., 2014; Mills et al., 2019). Also, even though some studies have suggested that it is best to desludge septic tanks (for example) every 2-5 years depending on number of users (Gill et al., 2016; Mehta et al., 2019), some systems are not emptied for up to 20 years and end-up with solidified sludge that are really difficult to remove (ISF-UTS and SNV 2019; Mehta et al., 2019). This practice is prevalent in most developing countries due to considerable technological and social obstacles (Mills, 2013; Peal et al., 2014, Kirsch and Hammersley-Mather, 2017; Balasubramanya et al., 2017) where sanitation facilities such as latrines/ toilets are mostly constructed poorly with sub-standard materials and limited spaces. Also, desludging vehicles and equipment are hindered due to poor accessibility, high exposure to faecal matter during collection and transportation, as well as blockages from the use of bulk materials from anal cleansing, menstrual hygiene and solid waste disposal (Thye et al., 2011; Nakagiri et al., 2016;
Kirsch and Hammersley-Mather, 2017). This is then compounded by the accumulation of faecal sludge in the environment and human settlements when emptying is delayed and unsafe (Dodane et al., 2012; Strande et al., 2018; Schoebitz et al., 2017). A study of 12 cities across Africa, Asia and South America showed that in some situations faecal sludge remained buried even when the containment was full and in other cases some users adapted their containers so that they could continue using them even after they had filled up by allowing the contents to overflow into an open drain or local informal sewer (common in Bangladesh and Indonesia) (Mills, 2013; Strande et al., 2018). Also, in Tanzania, households delayed emptying of toilets/latrines as long as possible, and then resorted to unsafe practices like 'flooding out' (Jenkins et al., 2015). Most of the sewage, faecal sludge and almost all of the septage generated by an average Indian city is disposed of untreated into open drains and peri-urban fields (Prasad and Ray, 2019).

This prompted the need to consider how individual and social perceptions could influence sanitation behaviour and how understanding this relationship could improve behaviour change intervention strategies for sanitation practices. Previous studies reveal that perception could create appropriate attitudes that lead to intentions to perform a desired behaviour (e.g., scheduled emptying for safely managed sanitation). They suggest that perception and behaviour are intimately linked; and the magnitude of the perceptual input is positively related to the magnitude of the resulting behavioural effects (Bargh et al., 1996a (Social ignition: the automatic activation of motivational states. New York University. Unpublished manuscript); Bargh et al., 1996b; Dijksterhuis and van Knippenberg, 1998). Perception forms behavioural representations that are automatically activated in memory, and once activated, can guide actual attitudes, intentions and then behaviour (Bargh and Chartrand, 1999; Bargh and Ferguson, 2000). Perception, in this case, refers to an understanding of the world constructed from information obtained by sensual interactions (Scherer and Walbott, 1994; Lewis, 2001) and personal experiences of the phenomena, causes and its effects, which then influence corresponding actions taken by individuals, groups or communities (Prinz, 1990, Bagheri et al., 2008; Cookey et al., 2016). Therefore, emptying perceptions of onsite sanitation systems (OSS) \{or non-sewered sanitation systems (NSS)\} could create attitudes that lead to certain intentions, which then finally result in the performance of timely and safe emptying behaviour.

Over the years there have been several sanitation behaviour change intervention programmes to combat these deleterious practices, but it has been argued that only very little change has occurred, while many of these programmes do not target 'emptying behaviour'. There are, however, no studies that address why these programmes failed. Previous studies on NSS/OSS systems emptying have mainly focused on technology, infrastructure, enabling environment, cost recovery and business models (Chowdhry and Koné, 2012; Kengne et al., 2011; Peal et al., 2014; Jenkins et al., 2015; Strande et al., 2018) and only very few on the psycho-social-cultural factors that influence current emptying behaviour. Moreover, these few studies concentrated on identifying behavioural factors responsible for unsafe and delayed emptying practices (Harper et al., 2018; Kugedera, 2019). The critical role of perception as a behavioural determinant has not been considered in studies, except as descriptive elements in some water, sanitation and hygiene (WASH) conceptual models (Jenkins and Scott, 2007; Curtis et al., 2009; Curtis et al., 2011; Devine, 2009, 2010; Figueroa and Kincaid, 2010; Mosler, 2012; Wood et al., 2012; Dreibelbis et al., 2013; Daniel et al., 2018; Seimetz et al., 2016). Particularly, Rainey and Harding (2005) identified individual perception of susceptibility and severity in 
their household water treatment behaviour model (which is not directly a sanitation focus) (Curtis et al., 2009; Charcot, 1886; Dreibelbis et al., 2013); while Mosler (2012) included the indicators of the perception of vulnerability and severity in his risks, attitude, norms, abilities and self-regulation (RANAS) behaviour change model (Dreibelbis et al., 2013; James, 1890). In the course of in-depth literature review, it became obvious that no study has committed to explore the role of perception in sanitation behaviour and change interventions. As the main study from which the focus of this paper was drawn highlighted the influence of perception on sanitation behaviour, it made sense to further explore the linkages revealed by the data (Kugedera, 2019).

Therefore, this paper seeks better perspectives on whether the perceptions of OSS/NSS users/owners provide better insights for designing emptying behaviour change intervention programmes? The objective is to determine if OSS/NSS emptying perceptions influenced the adoption of household/community emptying behaviours in the study area and to highlight the need for more studies on the influence of perception on sanitation behaviour (in this case emptying) in order to develop appropriate fit-forpurpose sanitation behaviour change intervention programmes. The paper attempts a novel move to identify types of OSS emptying perceptions with relevant cues and strenghteners, as well as some corresponding management strategies. Moreover, then subsequently, explore perception management as a key ingredient in designing, planning and implementing effective NSS/OSS emptying behaviour change intervention programmes to achieve safely managed practice. One key offshoot of the study is the urgent need for in-depth study on the perceptions that influence sanitation behaviour and how to predict perception and behaviour for appropriate and context-specific change interventions. This paper is divided into five sections: the first section introduces the concept of perception in onsite sanitation emptying, followed by the case study area with extensive deliberations on issues of onsite sanitation emptying, as well as its impacts on the ecosystems and surrounding environments. The next section addresses the methodology of the study, which is followed by the presentation of the results of the study. The paper ends with discussions, recommendations and conclusion for the management of onsite sanitation emptying perceptions to achieve the desired emptying behaviour.

Theoretical foundation. Previous studies have highlighted the linkages between perceptions and behaviour whereby perception triggers the tendency to behave in a corresponding manner. (Bargh, and Ferguson, 2000; Bargh et al., 1996b; Dijksterhuis and van Knippenberg, 1998). This is based on the assumption that perception and/or activation of a perceptual representation could lead to the corresponding overt attitude and intention that results in the performance of the desired behaviour (Koffka, 1925; Piaget, 1946; Berkowitz, 1984; Carver and Scheier, 1981; Mischel, 1973; Bargh et al., 1996a (Social ignition: the automatic activation of motivational states. New York University. Unpublished manuscript); Dijksterhuis and van Knippenberg, 1998; Bargh and Ferguson, 2000). Several studies have shown that perceptual and behavioural representations are somehow intimately linked (Schank and Abelson, 1977; Vallacher, 1993; Jordaan and Jordaan, 1989; Bock, 1986/1989; Dijksterhuis and van Knippenberg, 1998); for instance, Bargh et al. (1996b) demonstrated the unconscious and unintentional effects of perception on behaviour by indicating that behavioural representations can be automatically activated in memory during perception, and once activated, can guide actual behaviour (Bargh and Chartrand, 1999). Thus, perception is formed by an experiencing person or perceiver who perceives something (either an object, person, situation or relationship) in the context of the situation in which the objects, events or person are perceived; thus, the processing perception starts with sensual experiences of multiple stimuli and ends with the formation of percepts (Dell, 1986; Lewis, 2001). This implies that people are not only unaware of the information that is activated during the normal course of perception, but also of the way in which such information guides their judgements and impressions of the world around them (Bargh, and Ferguson, 2000). Furthermore, the focus of any perception will dictate the level of behavioural standard that becomes salient; and then subsequently determines what action is undertaken (Dijksterhuis and van Knippenberg, 1998).

Perhaps, then, identifying the perceptions of OSS/NSS users and emptiers could provide insights into understanding and predicting households' and workers' sanitation emptying behaviour, especially as perception of certain actions can lead to the performance of those actions, and people exhibit imitative behaviour from an early age onwards and mimic everything (Saxena, 1971; Albarracín and Wyer, 2000; Ajzen, 1985; Bargh and Ferguson, 2000). Also, the influence of perception on behaviour has been shown to go beyond desirable behaviours because people can imitate undesirable perceptions. For instance, in a Tanzania study, a negative perception about certain types of toilet/latrine emptying services (i.e., manual and/or mechanical) in a community was significantly associated with the practice of allowing faecal sludge to overflow into the environment (flooding out) during rainy season (Jenkins et al., 2015). Furthermore, perception could override any formal rules of emptying standard and guideline requirements (Tom et al., 1987; Eidelberg, 1929; Cookey et al., 2016), which consequently affects compliance. Some studies have even suggested that perception-behaviour determinants are crucial to understanding a wide array of social psychological phenomena such as compliance and conformity, emotional and behavioural contagion, empathetic reactions, risks/ hazards, beliefs and norms, abilities and attitudes, imitating and modelling, mass media effects on behaviour, and behavioural confirmation of stereotypes (Bargh et al., 1996b; Dijksterhuis and van Knippenberg, 1998).

Perceptual cues provide the stimuli that trigger the actual perception that creates the attitude required to produce the intention to eventually perform the corresponding behaviour. If perception and its cues influence individuals, households and communities to develop sanitation emptying-related behaviour, then their emptying behaviours could be based on what is perceived and as influenced by the cues (Tom et al., 1987). Thus, emptying behaviour change should begin from perception modification (Bargh and Ferguson, 2000). In this paper, we have developed four-constructs of NSS/OSS emptying perceptionbehaviour determinants derived from the theory of Planned Behaviour (Ajzen 1985) and adopted from the RANAS model (Mosler, 2012): (i) perception of risks/hazards of emptying; (ii) perception of desired emptying behaviour; (iii) perception of emptying norms; and (iv) perception of emptying ability. In addition to the above, six perception cues were identified in this paper that could provide the necessary triggers for stimulating and priming actual emptying perceptions. These perception cues are: (i) past emptying behaviour; (ii) sanitation belief system; (iii) consequences of previous emptying experience; (iv) sanitation norms; (v) sanitation situational factors; and (vi) confidence in ability to empty facility effectively. Also, two perception strenghteners were also identified: (i) information, and (ii) cognitive processes. Figure 1 illustrates how perceptions could influence NSS/OSS emptying behaviour and the components are reflected in Table 1.

The assumption is that perception cues supported by appropriate information and the ability to cognitively process 


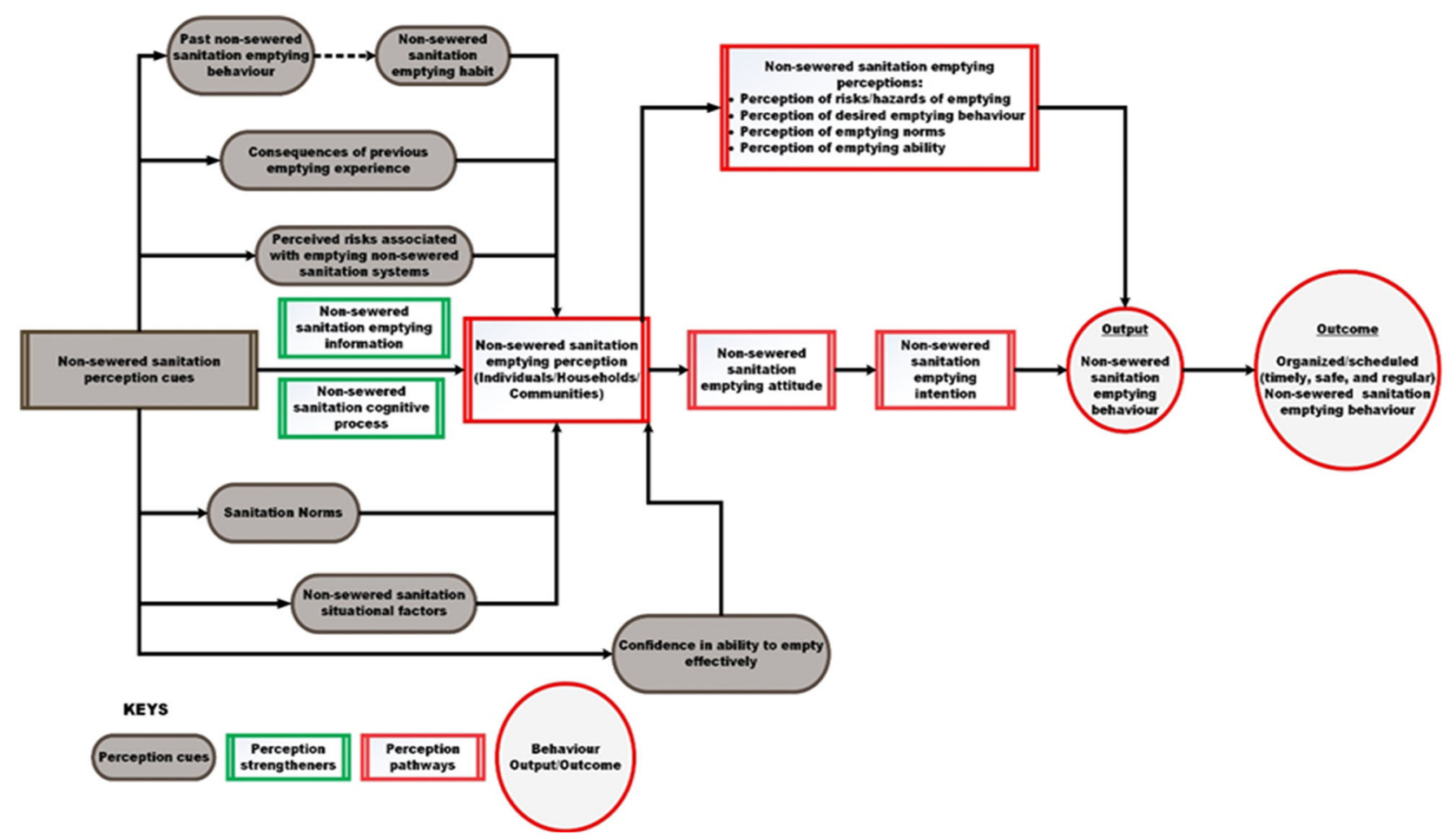

Fig. 1 A non-sewered sanitation emptying perception-behaviour trajectory. It attempts to illustrate perception cues supported by appropriate information and the ability to cognitively process knowledge will create perceptions that lead individuals, households and communities to produce corresponding attitudes, which then determine intentions towards a practice or activities that guide equivalent behaviour (i.e., either to empty or not to empty). It is based on findings of the interlinkages between perception and behaviour.

knowledge will create perceptions that lead individuals, households and communities to produce corresponding attitudes, which then determine intentions towards a practice or activities (Tankard and Paluck, 2016; Etikan et al., 2016) (in this case OSS/ NSS emptying) that guide equivalent behaviour (either to empty or not to empty). Deliberate and systematic management of these processes can be used to prime the kind of perceptions that lead to the desired behaviour (i.e., organised/scheduled emptying). This indicates that a comprehensive understanding of the psychosocial-cultural influences of perceptions on behaviour can provide concrete information on how and why residents choose a particular emptying behaviour and could be an entry point into designing an effective behaviour change intervention programme. We can, thus, conclude that to achieve a desirable emptying behaviour change with sanitation containment systems (i.e., toilets/latrines) will require proper understanding of emptying perceptions and with associated perception cues (perception stimulus).

\section{Materials and methods}

Study area-Khulna physical features. The corresponding study was carried out in Ward (smallest administrative urban unit) nine of Khulna City Corporation (KCC) made up of total population of 31,883 . Khulna is located in the south-western part of Bangladesh with a total population of 1.5 million and density of 32,859 persons $/ \mathrm{km}^{2}$ in a total area of 45.65 sq. $\mathrm{km}$ (Alam and Mondal, 2019) (Fig. 2). The city obtained its status as a formal town after the establishment of the municipality in 1884 during the British colonial regime (BBS, 2015) and is the third largest industrial city with the second largest seaport in Bangladesh. It is an important hub of trade and commerce, hosts many national companies and is one of the two principal naval-command centres of the Bangladesh Navy. Khulna is made up of 36 municipalities, 22 towns, 31 wards and 1134 slums (Kabir and
Salahuddin, 2014). The city is located in the south-western part of the country between Latitude $22^{0} 47^{\prime} 16^{\prime \prime}$ to $22^{0} 52^{\prime} 16^{\prime \prime}$ North and $89^{0} 31^{\prime} 36^{\prime \prime}$ to $89^{0} 34^{\prime} 35^{\prime \prime}$ East and lays along the banks of River Rupsha and Bhairab with an elevation of $4 \mathrm{~m}$ above sea level (Islam, 2016, Wikipedia contributors, 2020). The climatic conditions of Khulna is generally humid during summer and pleasant in winter with an average rainfall of $1605 \mathrm{~mm}$ and temperatures range of 12.5 to $35.5^{\circ} \mathrm{C}$. Khulna is considered the gateway of the Sundarbans, the world's largest mangrove forest and home of Bengal tigers. It is north of the Mosque city of Bagerhat, a UNESCO World Heritage Sites (WHO and UNICEF, 2017).

At a national scale, Bangladesh has made a remarkable improvement in sanitation coverage by reducing open defecation to $1 \%$ in 2015 with an improved sanitation coverage of $61 \%$ (Opel et al., 2012). However, $28 \%$ of the population still use shared latrines and $10 \%$ use unimproved latrines (Opel et al., 2012). Khulna city relies fully on on-site sanitation technologies such as septic tanks, pour flush and pit latrines. Septic tanks are dominant in the city centre in multi-storey buildings, whereas peri-urban areas and low-income communities mainly utilise pit latrines (Roy, 2014; Eawag/Sandec, 2015; SNV, 2014). The city has one decentralised wastewater treatment plant designed to handle final treatment and disposal of faecal sludge from on-site sanitation systems (Ross et al., 2016a, 2016b).

Institutional arrangement for non-sewered sanitation systems. The institutional arrangement for delivering NSS and faecal sludge management services in Khulna is vested in two government organisations: Khulna City Corporation (KCC) and Khulna Water Supply and Sewerage Authority (KWASA). Both are part of the Local Government Division of the Ministry of Local Government Rural Development and Cooperatives (MoLGRD\&C) (SNV, 2014). The Conservancy Section of KCC is the main unit responsible for the provision of sanitation services, 
Table 1 Interpretation of components of the non-sewered sanitation emptying perception-behaviour determinants.

\section{Components}

Emptying perceptions

Perception of risk/hazards of emptying

Perception of desired emptying behaviour

Perception of emptying norms

Perception of emptying ability

Perception cues

Past emptying behaviour

Sanitation belief system

Consequences of previous emptying experience

Sanitation norms

Sanitation situational factors

Confidence in ability to empty facility effectively

Perception strenghteners

Information

Cognitive processes

\section{Interpretation}

Perceived susceptibility or vulnerability to the emptying behaviour and severity of the expected consequences (positive and/or negative) that may result from performing that behaviour (Hochbaum, 1958; Rosenstock, 1966; Becker, 1974; Sharma and Romas, 2012; Morris et al., 2012; Mosler, 2012). Perceived attitude and the intention that support the performance of the desired emptying behaviour is dependent on one's attitude and intention to perform the appropriate emptying behaviour, in this case scheduled emptying (Fishbein and Ajzen, 1975; Funk and James, 2001/2006; Grizzell, 2007; Mosler, 2012; Neil et al., 2016; Loritoa et al., 2019).

Perceived norms based on their unique local experiences that become a reality to guide behaviour, even when the perceptions are inaccurate. Its unique feature is the emphasis on social influence, external and internal social reinforcement (Tankard and Paluck, 2016; Wicker, 1969; Bandura, 1971; Fishbein and Ajzen, 1975; Chartrand and Bargh, 1999; Munro et al., 2007; Mosler, 2012; Neil et al., 2016).

Perceived ability and self-efficacy to effectively perform the desirable emptying behaviour, in this case scheduled emptying. It is influenced by a person's specific capabilities and situational (barriers and facilitators) factors (Bandura, 1971/2000/2004; Gollwitzer and Sheeran, 2006; Schwarzer, 2008; Mosler, 2012).

Priming of future practice to influence current perception based on past performance that determine whether to repeat that emptying behaviour or not (Liska, 1984; Eagly and Chaiken, 1993; Albarracin and Wyer, 2000; Fuster and Bressler, 2015; Hollingworth and Barker, 2017).

The belief systems of individuals, households, and communities could create the perception that may influence emptying behaviour. Perceptual belief systems are much richer, detailed and a good behaviour determinant in their content (Armstrong, 1961; Rosenquist, 2005; Koottatep et al., 2019). The consequences (positive or negative) of previous emptying experiences may likely influence the subsequent actual emptying perception that could determine future emptying behaviour to be adopted (Skinner, 1953).

Traditions, customs, and religious beliefs provide cues that activate corresponding emptying perceptions that could trigger the attitudes and intentions to act on that behaviour (Darnton, 2008; Mosler, 2012; Tankard and Paluck, 2016).

The unique and dynamic contexts that influence emptying perception-behaviour adoption. Issues such as the household's educational and socio-economic levels, the quality of facilities, compliance to regulations and enforcement of sanitation laws, and general environmental conditions of the location will definitely influence emptying perception-behaviour links (Mosler, 2012; Koottatep et al., 2019; Navarro, 1994; van Vliet et al., 2011; Ahmed and Hassan, 2012; Novotny et al., 2018).

The self-accepted capabilities that activate perceptual representations, which may produce the desired corresponding emptying behaviour (Bruner, 1957; Prinz, 1990; Dijkersterhuis and Knippenberg, 1998; Ferguson and Bargh, 2004; Canal-Bruland and Van Der Kamp, 2009; Mosler; 2012).

Perceptual actions and decisions guided by detail of instructions that influence what is being perceived. The right kind of emptying information provides the stimulation needed to guide emptying perception that produce the desired behaviour (Park et al., 1988; Brewer and Lambert, 2001; Tacca, 2011; Mulder, 1979; Chemero, 2003).

Knowledge and understanding captures roughly the capacity and thoughts that could exert significant influences on perception-behaviour determinants (Fodor, 1983; Firestone and Scholl, 2015; Sydhagen, 2017; Michel, 2019). especially on-site sanitation facilities emptying services, street sweeping, surface drainage cleaning and solid waste management (Mansour et al., 2017). KCC along with various NonGovernmental Organisations (NGOs) and informal private service providers are major stakeholders responsible for the provision of sanitation systems emptying services in many parts of the urban areas (Mansour et al., 2017). KWASA is a corporatized utility with a mandate to ensure water supply, drainage and sewerage services. However, in the case of Khulna, where the city is fully dominated with NSS infrastructure, KWASA may have to require different governance and management strategies to improve their capacity and competencies to improve service delivery for OSS. Also, major sources of financing for activities of KWASA are mainly from tariff revenues. However, capital investments are usually financed by the central government (MoLGRD\&C, 2017).
The main legal instruments that specifically clarify the roles and responsibilities of the various actors involved in the broader faecal sludge management (FSM) with reference to on-site sanitation infrastructure emptying services is the Institutional and Regulatory Framework for Faecal Sludge Management (IRFFSM) of 2017 (BNBC, 2014). IRF-FSM clarifies the roles and responsibilities for FSM, re-affirming Ministries' lead role in policy making, City Corporation and municipalities' roles in ensuring services, and the need for partnership with Khulna Water Supply and Sewerage Authority (KWASA) where relevant. The framework also make provisions for guidelines on the design of households and communal treatment facilities; specifies the role of private sector participation; and identifies the need of the Ministry of Local Government Rural Development and Cooperatives (MoLGRD\&C) to set up a unit within the KCC and Khulna's 36 municipalities for the delivery of FSM services with special 


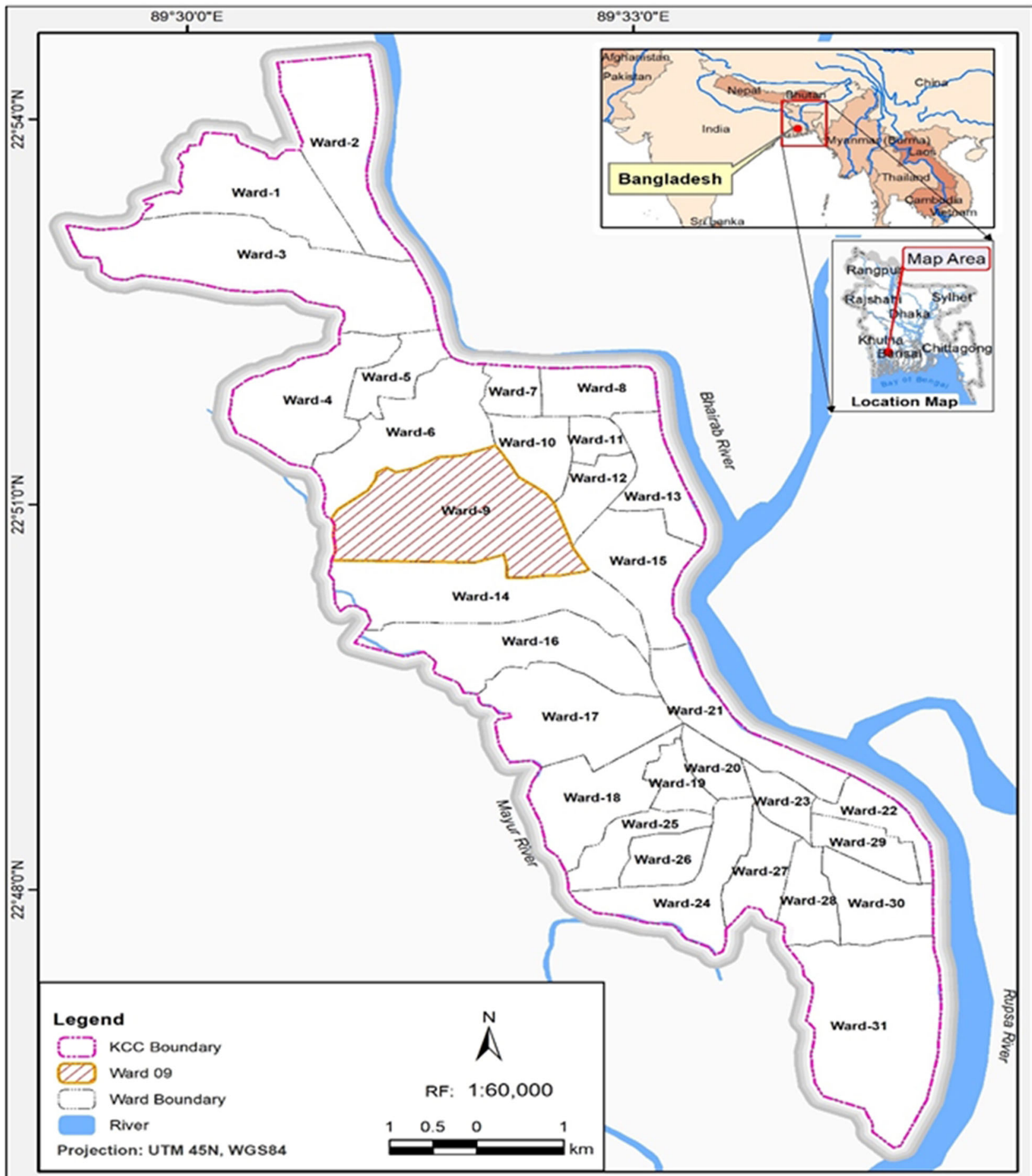

Fig. 2 Map of Khulna City Corporation. Map of Khulna City Corporation showing the location of Ward 9 in the study area and other specific study sites.

reference to emptying of on-site sanitation infrastructure (MoLGRD\&C, 2017, BNBC, 2014).

In addition, priorities are given for the: (i) management of faecal sludge from septic tanks and pit latrines such that all sludge should be collected, transported and disposed, safely and regularly in an environmental friendly manner; (ii) develop innovative technologies that are appropriate to local conditions for emptying, collection, treatment and safe disposal of faecal sludge; (iii) build FSM and regulatory capacities of local governments in Khulna; (iv) implement relevant national sanitation policies and laws, as well as bylaws for timely, safely and regularly emptying of septic tanks and pit latrines; and (v) provide technical and business support to the private sector in sludge management, recycling and sale of compost or other products (MoLGRD\&C, 2017). The Bangladesh National Building Code $(\mathrm{BNBC})$ is another critical legal instrument relevant for improved management of OSS emptying and other associated technical operations and maintenance (Repon et al., 2015). 


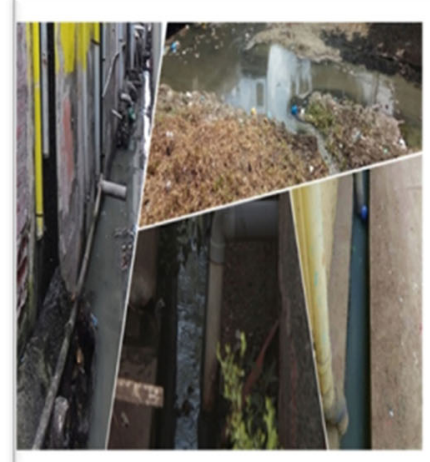

(I)

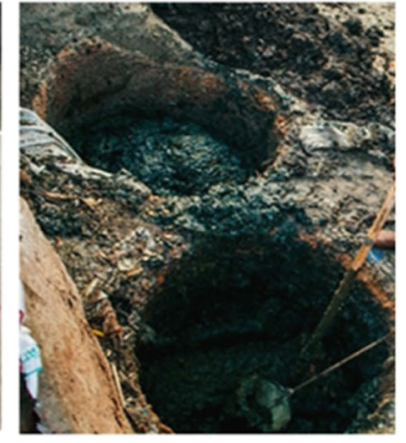

(II)

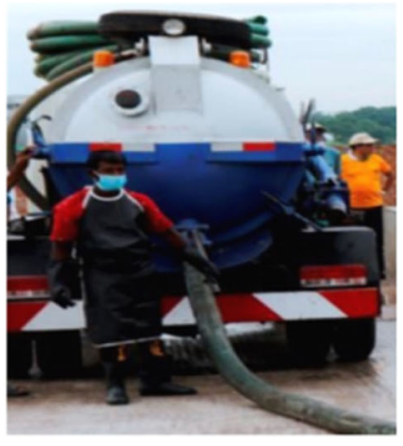

(III)

Fig. 3 Shows some on-site sanitation emptying practices in Khulna. (I) On-site sanitation systems discharging untreated effluent into public drains; (II) Manual emptiers in operations; and (III) Motorised on-site sanitation emptying trucks discharging to treatment plant.

This regulation makes provision for the formal approval of septic tank design and construction with appropriate technical specifications for controlled discharge of effluents into the subsurface disposal field and/or seepage pits where public sewers are not available. This regulation prohibits the discharge of effluents from septic tanks into open water sources and prescribe minimum septic tank capacity for different types of households. Also, the BNBC makes provision for the emptying frequency of a septic tank, which should be performed within a minimum of 6 months interval and maximum once a year (Repon et al., 2015).

On-site sanitation systems emptying services. Emptying on-site sanitation systems in Khulna is demand-driven, which makes homeowners and/heads of households responsible for engaging service providers and paying for the services. The OSS emptying is mostly done by informal workers known as 'sweepers' (Clasen et al., 2010), and emptying behaviour could be characterised as being reactive and unsafe (Wikipedia contributors, 2020, Mondal, 2018, ISF-UTS and SNV, 2019). This makes for unsystematic and inadequate emptying that often contaminates the environment and poses serious public health hazards to the vulnerable population (Ross et al., 2016a, 2016b; Opel, 2012). Studies have shown that inappropriate designs of on-site sanitation infrastructure (due to non-compliance to BNBC Code of Practice) impact negatively on the functionality and serviceability of the systems. Consequences from this non-compliance include frequent effluent overflow and discharge of faecal sludge into waterbodies or open drains of the Khulna communities (SNV, 2014). With increasing population density, high water use and table, septic tanks are usually overloaded resulting in the discharge of large volumes of untreated effluents directly into the local environment via dysfunctional soakaways and/or by deliberate direct discharge to surface/storm-water drains.

On the other hand, pit latrines also fill up quickly and require frequent emptying and likewise large volumes of inadequately treated effluents are discharged into the nearby environment. Also, pour flush toilets are directly connected to the drains without any form of onsite containment measures (MoLGRD\&C, 2017) (Fig. 3). Studies reveal that more than half of the households, irrespective of wealth situation, either carried out reactive/emergency emptying (the households contact manual and/or mechanical/motorised emptiers when the systems overflow or stop working) or do not empty at all (Ross et al., 2016a, 2016b; SNV, 2014; Wikipedia contributors, 2020; Mondal, 2018) contrary to the BNBC Code for 6-12 months (Repon et al., 2015). More than 81 percent of the toilets/latrines' emptying in
Khulna are performed manually without safety precautions, appropriate PPE and working tools; and another 17 percent use a combination of motorised and manual services (Ross et al., 2016a, 2016b; Mara, 1996; Chowdhry and Koné, 2012; SNV, 2014). There are only two formally established motorised on-site emptying service operators in Khulna (Conservancy Department of KCC and Community Development Committee). KCC provides services to mostly commercial, public and private organisations, as well as to certain households with spacious access road connections. Some mechanical/motorised emptying services are challenged by blockage of hosepipes and pumps and many narrow roads that make accessing individual households difficult (SNV, 2014).

Access is one of the major hindrance to safe mechanical emptying in the study area. To address the challenge of access, Vacutug (ideal emptying equipment for areas with limited access and low-income-densely-populated settlements) was designed to provide emptying services to narrow paths of Khulna (Strauss and Montangero, 2002; Montangerop, 2004). However, majority of the households still use unsafe manual emptiers because they are easily available, affordable and flexible with time (Mara, 1996). There are approximately 150-200 active informal manual emptiers (or Sweepers) providing emptying services in Khulna and can empty around $68.7 \mathrm{~m}^{3}$ of faecal sludge per day (Ross et al., 2016a, 2016b).

Sampling design. The secondary data for this work were gathered from literature and official documents of relevant government and non-governmental organisations and the primary data were generated from structured household surveys with assistedadministered questionnaire, face-to-face key informant interviews, group interviews, and structured observations (Kugedera, 2019). The motivation for key informant and group interviews was to dig deeper with more complex questions so as to get more detailed responses on OSS/NSS emptying perceptions and behaviours. This is because these community experts and householders with their particular knowledge and understanding could provide better insights on the nature of the emptying problems in the community. In addition, group interviews and structured observations provided a unique way of reducing interviewing biases and ensure collaboration of information among the group in order to establish information validity, as well as the intensity of the OSS/ NSS emptying problem. The structured household questionnaire sought to identify key demographic, socio-economic and emptying perceptions and their corresponding behaviours. 
A mixed sampling method of random and convenience sampling (Cochran, 1977; Etikan et al., 2016; Kugedera, 2019) were adopted for structured household questionnaire surveys and the interviews. This sampling method was chosen to allow for both breadth and depth in understanding of how situational factors prime perception to influence emptying behaviour (Bornstein, 2013) and to remove bias from OSS/NSS selections for the survey. This mixed sampling method was because easy to execute, less time consuming and less expensive given the fact that the data for this study was collected within three months (Sudman and Bradburn, 2004). All research instruments were translated into Bengali language, verified by a panel of three experts before they were administered by eight trained research assistants as enumerators for the household survey. Also, three research assistants helped in the translation of the key informant and group interviews, as well as in data entry. Sampling size for OSS/NSS facilities this study was computed using equation I presented below (Daniel and Cross, 2018; Bernard, 2002; Kugedera, 2019):

$$
n=N^{*} X /(X+N-1),
$$

where: $X=Z_{\alpha / 2}{ }^{2} * p^{*}(1-p) / \mathrm{MOE}^{2} ; Z_{\alpha / 2}$ is the critical value of the Normal distribution at $\alpha / 2$ (e.g., for a confidence level of $95 \%$; $\alpha$ is 0.05 and the critical value is 1.96); MOE is the margin of error (set at 0.005 for this study); $p$ is the sample proportion expected to show how emptying perception cues and the actual perception influences emptying behaviour (set at $5 \%$ for this study); and $N$ is the population size (Daniel and Cross, 2018; Bernard, 2002; Kugedera, 2019).

Khulna Ward 9, the study area, had a population of 691 on-site sanitation systems based on a recent study of Mondal et al. (2018). From Eq. 1, the minimum sample size for OSS/NSS facilities was estimated to be 67 , however, 80 households with NSS facilities were enroled in the study to cater for dropouts. Each OSS/NSS facility is used by an average of five households with five family members, making the sample population covered to be $\sim 2000$ individuals. The heads of households, workers, professionals and relevant government officials were surveyed for their OSS/NSS emptying perceptions and challenges they face. For a person to participate in the household survey, he or she had to be the house-owner or anyone with the authority and power to decide on when and how to empty sanitation containment systems and these included the partners, elder children or senior tenants (Kugedera, 2019).

Participants for key informants' interviews were selected through purposive sampling (Tongco, 2007; Creswell, 2009) and those proficient and well-informed people with tacit knowledge and experience in faecal sludge management and on-site sanitation emptying procedures (Creswell et al., 2011; Navarro, 1994). On the whole, six key informants were selected for this aspect of the field study, two from the Conservancy Department of Khulna City Corporation (KCC) (the municipality unit responsible for carrying out emptying services) and Ward 9 Councillor, two from an international NGO involved in urban WASH programme, one from a local NGO and one community development officer involved in sanitation-related activities in the study area. Participants for the group interviews were also purposively selected from the slum area of Khulna Ward 9. One participant was identified from each Community Toilet Management Committee and subsequently five females and six males were selected to participate in the group interview (Kugedera, 2019).

Household questionnaire survey. A household non-sewered sanitation system emptying survey was carried out on the selected householders at Ward 9, Khulna (Bangladesh) on-site sanitation systems/non-sewered sanitation systems between the period of December 2018 and February 2019. Trained enumerators administered a well-structured questionnaire to 80 identified respondents. The survey targeted household heads, their partners or any other person with the authority and power to decide on when and how to empty the toilet/latrine containments. The participants were drawn from the planned residential, mixed-use and slum areas of the Khulna Ward 9. The questionnaire had 56 questions divided into three sections. The first main section assessed the situational factors as a perception cue aimed at the respondent's backgrounds, which addressed issues of livelihoods, education, regulatory enforcement, socio-economic, on-site sanitation infrastructure use and emptying-related issues, as well as environmental conditions of the study area. This aspect of the study was based on the assumption that situational factors do exert a certain degree of linkages in emptying perception-behaviour adoption (Van Vliet et al., 2011; Ahmed and Hassan, 2012; Koottatep et al., 2019; Schoebitz et al., 2017; Yin 2003; Kugedera 2019).

The second section involved the assessment of the respondents' on-site sanitation past emptying behaviour cues as influencers of perception to trace the attitude and intention that determine the actual emptying behaviour. Some of the information sourced from the respondents included; the last time their on-site sanitation systems were emptied; how it was emptied (manual or mechanical/motorised); and whether it was emptied before or after faecal sludge was seen overflowing from the system. Also, the enumerators carried out onsite sanitation facility inspections/ audits to determine the quality of the construction, operations and maintenance, and then determine if the system was directly connected to the drain; and if there was evidence of faecal sludge overflowing from the system or if there were faeces around the sanitation containment systems (Dreibelbis et al., 2013; Schoebitz et al., 2017; Kugedera, 2019). Data generated from this section was used to determine perception cues of past emptying behaviour. The third section was a mix of qualitative and quantitative questions designed to assess the emptying perception-behaviour determinants of non-sewered sanitation systems. Based on this, four-constructs of perception-behaviour determinants were developed for this study: perception of risks/ hazards of emptying; perception of desired emptying behaviour; perception of emptying norms; and perception of emptying ability. The entire questionnaire was then translated into Bangla language and verified by Bangla-English specialist. Also, pretesting of the questionnaire was done on ten nearby housing units who agreed to participate. Amendments were made to the questionnaire based on the feedback from pretesting before the actual commencement of the field work. The survey was conducted with a team of eight trained Bangla-speaking field assistants.

Key informant face-to-face and group interviews/observations. Structured key informant face-to-face interviews were conducted with six key informants who had vast experiences with practical and professional knowledge in faecal sludge management and onsite sanitation emptying practices. The idea was to dig deeper into the perceptions surrounding the adoption of the predominant onsite sanitation emptying behaviour in the study area. The key questions asked followed the structure of the survey questionnaire assessing the influence of emptying perceptions that eventually determined the prevailing emptying behaviour in the study area.

The group interview, which lasted for $60 \mathrm{~min}$, was conducted with the representatives of the Community Toilets Management Committees from Bastuhara Slum area of Khulna. This was a substitute measure after realising that collection of additional data at household level was not feasible given the fact that most of the 
household members relied on shared community toilets, where emptying decisions are a shared responsibility. Hence, it was necessary to gather data from those responsible for the management, operations and maintenance of such communal on-site sanitation systems. A group interview guide was developed in English language and translated to Bangla. The key questions asked were on emptying perceptions and behaviour, as well as situational factors that influence emptying of on-site sanitation systems. The group interview was conducted at the community town hall and the process was supported by three research assistants.

The field visits to the case study area also provided the opportunity for direct and indirect observations of the various on-site sanitation infrastructure and the emptying practices in the study area. These observations provided another source of useful evidence concerning the understanding of the perceived barriers for adoption of scheduled emptying behaviour. Also, the interviews were used to seek further clarification on issues raised from the survey thereby helping in validating and giving further explanation of the study findings.

Data analysis. Survey responses were analysed using descriptive statistics with the help of Excel Statistical packages. Qualitative data generated were analysed using thematic approach (USAID, 2010; Creswell et al., 2011; Hashimoto, 2019). Basic statistics including mean, frequency and percentages were computed for the results.

\section{Results}

Respondents' profiles and onsite sanitation systems'. Table 2 shows the profiles of the respondents as supported by interviews and observations. There were more males (81\%) than females (19\%). The result indicated that a relatively large proportion of the sampled population were between the ages of 40-55 years (40\%) while $21.3 \%$ were between the ages of $19-39$ and $38.8 \%$ were over 55 years. This implies that the respondents had experience on various issues relating to emptying of onsite sanitation systems and could have built-up enough perception on their households and community sanitation-related matter. Education-wise, $41 \%$ acquired tertiary education, $15 \%$ graduated from higher secondary education, $15 \%$ attended secondary education, 20\% acquired primary education and 9 did not received any formal education. The respondents' educational levels were enough to understand sanitation challenges of the community and issues around households' onsite sanitation emptying processes and express same clearly. Majority of the respondents (53\%) lived in the planned residential area while $34 \%$ lived in the mixed areas and $15 \%$ were located in the slum areas of Khulna Ward 9. The duration of stay (i.e., amount of time someone has lived in Khulna) of the respondents in the communities indicated that $76 \%$ had stayed for 10 years and above, $11 \%$ had stayed between $5-10$ years, and $13 \%$ had stayed for $<5$ years. The longer the amount of time the respondents lived in the communities indicate better familiarity with their communities and grounded perceptions on emptying onsite sanitation systems.

The distribution of respondents' livelihood activities were: formal employment in public and private sector 50\%, informal employment such as self-employment with no formal contracts accounted for $41 \%$, farming (crops and aquaculture) $4 \%$ and foreign remittances $5 \%$. The study also revealed that the average monthly income per household in the study area ranges from 1-118 USD (24\%), 130-236 USD (24\%), 247-412 USD (33\%), and $>412$ USD (20\%). Majority of the respondents (91\%) spent less than or equal to their monthly income while $8 \%$ spent more than their monthly income.
Table 2 Respondents profiles and characteristics of their onsite sanitation systems as well as their emptying practices.

\begin{tabular}{|c|c|c|c|}
\hline Characteristics & Description & \# & $\%$ mean \\
\hline \multirow[t]{2}{*}{ Sex } & Male & & 81 \\
\hline & Female & & 19 \\
\hline \multirow[t]{4}{*}{ Age } & $50-60$ years above & & 39 \\
\hline & $31-49$ years & & 40 \\
\hline & $20-30$ years & & 21 \\
\hline & Less than 20 years & & - \\
\hline \multirow[t]{5}{*}{ Level of education } & Non-formal & & 9 \\
\hline & Primary & & 20 \\
\hline & Secondary & & 15 \\
\hline & Higher secondary & & 15 \\
\hline & Tertiary & & 41 \\
\hline \multirow[t]{4}{*}{ Livelihood } & Formal employment & & 50 \\
\hline & Farming & & 4 \\
\hline & Remittances & & 5 \\
\hline & Informal employment & & 41 \\
\hline Monthly & $1-100$ & & 24 \\
\hline \multirow[t]{3}{*}{ income (USD) } & $101-200$ & & 24 \\
\hline & $201-300$ & & 33 \\
\hline & 301-400 and above & & 20 \\
\hline \multirow[t]{3}{*}{ Place of residence } & Planned residential area & & 53 \\
\hline & Mixed-use area & & 34 \\
\hline & Slum area & & 14 \\
\hline \multirow[t]{3}{*}{ Duration of stay } & 10 years and above & & 76 \\
\hline & $5-9$ years & & 11 \\
\hline & Less than 5 years & & 13 \\
\hline \multirow[t]{3}{*}{ Study demographic } & $\begin{array}{l}\text { Total number of OSS/NSS } \\
\text { surveyed }\end{array}$ & 80 & \\
\hline & $\begin{array}{l}\text { Total number of households } \\
\text { cover: }(5 \text { households per } \\
\text { OSS/NSS } \times 80 \text { ) }\end{array}$ & 400 & \\
\hline & $\begin{array}{l}\text { Total number of population of } \\
\text { users of OSS/NSS: ( } 5 \\
\text { households } \times 5 \text { family } \\
\text { members per OSS/NSS } \times 80 \text { ) }\end{array}$ & 2000 & \\
\hline Type of OSS in use & Latrine on top of the drain & & 9 \\
\hline Pit latrine & & 15 & \\
\hline $\begin{array}{l}\text { Septic tank with } \\
\text { soak-away pit }\end{array}$ & & 8 & \\
\hline $\begin{array}{l}\text { Septic tank with a } \\
\text { direct connection to } \\
\text { the drain }\end{array}$ & & 69 & \\
\hline \multirow{5}{*}{$\begin{array}{l}\text { OSS/NSS emptying } \\
\text { practices }\end{array}$} & Within the last 6 months & & 11 \\
\hline & Within the last 12 months & & 12 \\
\hline & Within the last 3 years & & 9 \\
\hline & More than 3 years ago & & 23 \\
\hline & Never emptied & & 48 \\
\hline \multirow[t]{2}{*}{$\begin{array}{l}\text { Current emptying } \\
\text { behaviour }\end{array}$} & $\begin{array}{l}\text { Emptied after faecal sludge } \\
\text { overflow }\end{array}$ & & 57 \\
\hline & $\begin{array}{l}\text { Emptied before faecal sludge } \\
\text { overflow }\end{array}$ & & 43 \\
\hline \multirow{4}{*}{$\begin{array}{l}\text { OSS/NSS emptying } \\
\text { methods } \\
\text { OSS/NSS effluent } \\
\text { discharge points }\end{array}$} & Manual emptying & & 64 \\
\hline & Mechanical emptying & & 36 \\
\hline & $\begin{array}{l}\text { Discharge to storm- } \\
\text { water drains }\end{array}$ & & 66 \\
\hline & $\begin{array}{l}\text { Discharge into surrounding } \\
\text { environment }\end{array}$ & & 34 \\
\hline
\end{tabular}

The results showed that $54 \%$ of the respondents had no children below the age of 5 years in their homes while $38 \%$ had one child and $9 \%$ had two children. Also, $50 \%$ of the respondents had no chronically ill persons in their households, $36 \%$ had (1) while $11 \%$ had (2) and $3 \%$ had (3). On the average, each on-site 


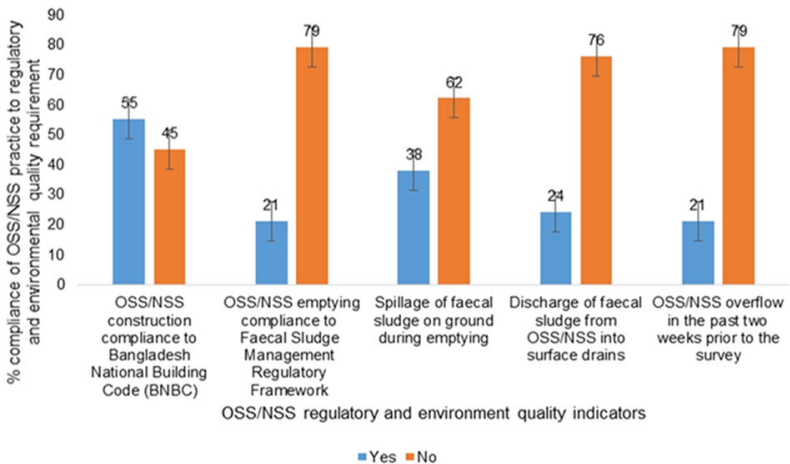

Fig. 4 Compliances rate of onsite sanitation systems/non-sewered sanitation systems (OSS/NSS) practices to regulatory and environmental quality requirements in Bangladesh. $A$ facility survey and observation of 80 out of the 691 on-site sanitation systems in Khulna ward 9 were carried out to determine compliance to Bangladesh National Building Codes. $45 \%$ of the OSS/NSS survey did not comply to construction guidelines of national building codes; on $21 \%$ complied to emptying guidelines in faecal sludge management regulations; 62 percent were not in compliance to spillage of faecal matter during emptying procedures while only $24 \%$ showed no discharge to surface drains and $21 \%$ had no indications of overflow into the environment. In summary, most of the OSS/NSS survey were not in compliance to any regulations and had failed in several aspects.

sanitation system was shared by five (5) households and each household had five (5) family members.

The majority of the respondents (69\%) used septic tanks with no soak-away pits, but directly connected to storm-water drains and $7 \%$ used septic tanks with soak-away pits while $15 \%$ used pour flush toilets connected to pits, and $9 \%$ used pour flush connected to surface drains. Forty-eight percent of these sanitation systems had been flooded before during rainy seasons while $43 \%$ had not experienced any flooding. A relatively large proportion of onsite sanitation systems visited during inspections and facility audits were in proximity to storm-water drains (56\%) while $11 \%$ were located near water ponds, $2 \%$ were very close to the canals, but were located far away from any water body. The findings also revealed that $44 \%$ of the onsite sanitation systems were not accessible by motorised/mechanical emptiers (vacuum trucks) and manholes of $13 \%$ of these systems were not easily accessible by the manual emptiers (Table 2).

Meanwhile, $48 \%$ of the systems have never been emptied, $23 \%$ were last emptied at least three years ago, $11 \%$ was emptied within the last six months, and $10 \%$ within the last 12 months while $9 \%$ were emptied within the last three years. However, $89 \%$ of the respondents had not emptied their system timely and safely while $11 \%$ had practised both timely and safe emptying. Of those respondents who had emptied their systems at all, 57\% emptied after faecal sludge overflow while $43 \%$ emptied before it overflowed. Also, $64 \%$ of those who emptied used manual operators while $35 \%$ used mechanical emptying.

Overall, 55\% of the respondents' OSS/NSS construction were in compliance with the provisions of the Bangladesh National Building Code (BNBC) while $45 \%$ were found to be noncompliant. Only $21 \%$ of the OSS/NSS emptying comply with Faecal Sludge Management Regulatory Framework of Bangladesh (Fig. 4). Physical facility inspection and audit of the sanitation systems revealed that $66 \%$ of the systems were seen directly discharging effluents into storm-water drains while 34\% did not discharge any effluent into the environment (Table 2). Spillage of faecal sludge on the ground during OSS/NSS emptying was reported by $38 \%$ of the respondents while $62 \%$ had no similar experiences. Also, 24\% of the observed systems were discharging faecal sludge directly into the drains while the remaining $76 \%$ did not release any faecal sludge into the environment. However, $21 \%$ of the onsite sanitation systems inspected/audited had overflowed in the past 2 weeks prior to the survey. This could indicate a perception that effluents are not as hazardous as faecal sludge (solids) (Fig. 4).

Perception of risks/hazards of emptying onsite sanitation system. This study revealed that $70 \%$ of the respondents do not perceive any negative consequences from unsafe and reactive emptying of OSS/NSS while $23 \%$ perceived that it might have some negative consequences, $4 \%$ perceived a high possibility for negative consequences and 3\% were neutral. This could explain the reactive/emergency emptying behaviour of the Khulna community. Meanwhile, $88 \%$ of the surveyed population perceived that their family members face some risks of being sick from exposure to faecal sludge overflowing from the containment systems while $6 \%$ agreed that there were certain risks of exposure, $4 \%$ were not aware of any potential risks and none of the respondents considered that there was zero risk to exposure. On the perspective of community risk perception, $45 \%$ of the respondents perceived that community members could fall sick from faecal sludge exposure due to system overflow, 25\% believed that there were some medium risks and 5\% saw a high risk level while $25 \%$ had no idea about the impact of community exposure to faecal sludge (Fig. $5 \mathrm{a} / \mathrm{b}$ ).

On the perception of risk-severity from unsafe and reactive emptying, $49 \%$ of the respondents considered the magnitude of severity of individual exposure to faecal sludge to be high while $28 \%$ perceived it to be of medium severity, but $22 \%$ considered it to be minimal and $1 \%$ did not know if there was any risk-severity from exposure to faecal sludge from sanitation facilities. On the other hand, $31 \%$ of the respondents perceived that the severity of exposure of family members to faecal sludge will be high, $44 \%$ perceived the severity to be medium, 24 believed it will be low and $1 \%$ were neutral. However, $1 \%$ of the respondents perceived that the magnitude of severity to the community as a whole will be high, $30 \%$ perceived the severity to be of medium effect while $33 \%$ believed that the severity will be low and $36 \%$ were ambivalent. In addition, the study revealed that $43 \%$ of the respondents perceived that the faecal sludge and effluents from their neighbours' onsite sanitation systems were more dangerous than the one from their systems, but $16 \%$ were of the opinion that the risks were the same while $41 \%$ were undecided.

Perception of desired emptying behaviour. The study revealed that $55 \%$ of the respondents perceived that engaging in scheduled (timely and safe) emptying is a tiresome process, while $28 \%$ were of the opinion that it is not tiresome and $17 \%$ were undecided. Also, $51 \%$ of the respondents perceived scheduled emptying behaviour as a costly venture while $28 \%$ felt that it was affordable and $21 \%$ were undecided. $98 \%$ considered that the desired (scheduled) emptying behaviour could improve their individual/ family health while $2 \%$ were undecided. $88 \%$ were of the opinion that it would have a positive impact on the community and $12 \%$ were undecided. Considering interaction with faecal matter, especially by seeing it in the drains and environment, about $38 \%$ of the respondents expressed high level of faecophobia (disgust), $26 \%$ expressed some mid-level faecophobia while 36\% rarely felt any form of disgust. However, only about $23 \%$ expressed gross (high level) disgust at effluents from onsite sanitation systems in the drains and/or environment while $43 \%$ sometimes (mid-level) were disgusted and 34\% rarely felt disgusted (Table 3 ). The dangerous perception indicated here is that effluents from these 


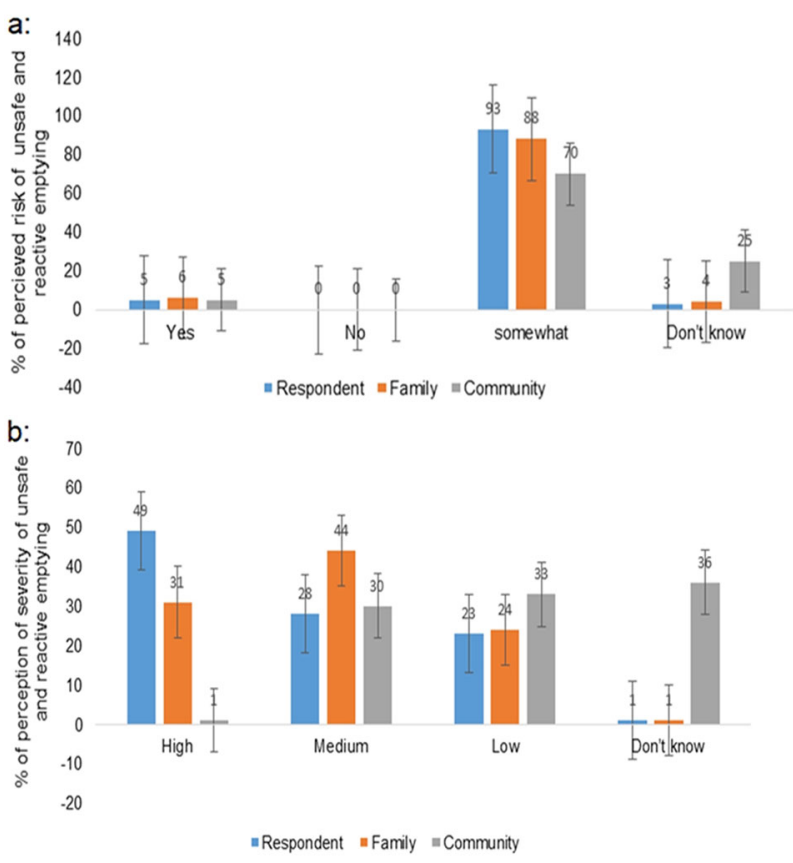

Fig. 5 Perceived risks and perceived severity of faecal sludge overflow from onsite sanitation systems in the study area. a Perceived risks of faecal sludge overflow from onsite sanitation systems (OSS) in the study area. Four-hundred households were surveyed using structured

questionnaires to determine respondents' perceived risks from unsafe and reactive emptying behaviour in Khulna Ward 9. Perception of certain risks of self ( $5 \%)$, family member (6\%) and community (5\%); perception of some risks to self (93\%), family (88\%) and community (70\%); undecided for self (3\%), family (4\%) and community (25\%); perception of no risk was zero in all; and $\mathbf{b}$ Perceived severity of faecal sludge overflow from onsite sanitation systems (OSS) in the study area. The respondents were also required to indicate their perceived severity from these unsafe and reactive emptying behaviours. Perception of high severity for self (49\%), family $(31 \%)$ and community (1\%); perception of medium severity for self (28\%), family (44\%) and community (30\%); perception of low severity for self (23\%), family (24\%) and community (33\%); undecided perception for self (1\%); family (1\%) and community (36\%). In summary, perceived risks and severity are considered less concerning to the community at large.

systems are not as bad as the solids (faecal sludge) and so can be tolerated.

Perception of emptying norms. The respondents' perception of the community and societal norms about onsite sanitation emptying showed that $86 \%$ of the respondents had seen some members of the community practicing scheduled emptying while $14 \%$ had not. Sixty-one percent perceived that there are community norms that disapprove of discharging faecal matter into the drains, however, $10 \%$ were of the opinion that such norms did not exist, and $29 \%$ were not sure. Meanwhile, $50 \%$ of the respondents perceived that they will not get approval from their reference/preference (people they respect and listen to) groups for indiscriminate discharge of effluents from their onsite sanitation systems into the drains and the environment, $8 \%$ believed they would get approval from their reference/preference groups while $42 \%$ were not sure. Also, $42 \%$ perceived that there is weak enforcement of laws regulating onsite sanitation systems' emptying practices by the appropriate city authority while only $10 \%$ of the respondents' perceived that relevant laws on emptying of onsite sanitation were enforced and $48 \%$ were neutral (Fig. 6).

\begin{tabular}{|llc}
\hline \multicolumn{2}{l}{ Table 3 Perception of scheduled (timely and safe) emptying } \\
behaviour. & & \\
Indicators & Description & $\%$ mean \\
\hline Practice of scheduled (timely and & Tiresome process & 55 \\
safe) emptying behaviour & Not tiresome & 28 \\
& Undecided & 17 \\
Perceived cost of scheduled emptying & Affordable & 28 \\
of OSS/NSS & Not Affordable & 51 \\
& Undecided & 21 \\
Scheduled emptying has a positive & Agree & 98 \\
impact on health/well-being of & Disagree & - \\
individual/family & Neither agree or & 2 \\
& disagree & \\
Scheduled emptying has a positive & Agree & 88 \\
impact on health/well-being of & Disagree & - \\
community & Neither agree or & 12 \\
& disagree & \\
faecophobia (disgust) with faecal & Very true of me & 38 \\
sludge discharge into the drains/ & Somewhat & 26 \\
environment & true of me & \\
& Untrue of me & 36 \\
faecophobia (disgust) with effluents & Very true of me \\
discharge into the drains/ & Somewhat \\
environment & true of me & 43 \\
& Untrue of me & 34 \\
& &
\end{tabular}

This was further reinforced by the key informant interviews where dissatisfaction with enforcement levels were predominant.

In the Khulna Ward 9 community, these emptying norms are present, e.g..: (i) most of the respondents had witnessed scheduled emptying behaviour at some point in-time but were not inspired to practice it; (ii) most of them also perceived that their community disapproved of desludging faecal matters into the drains and/or environment but carried on with the practice anyway; (iii) half of them also perceived that their reference/ preference groups will disapprove of indiscriminate desludging but still continued the behaviour; and (iv) the other half perceived that there was no indication of disapproval and so felt emboldened to continue in unsafe and untimely emptying behaviour.

Perception of emptying ability. Majority of the respondents (56\%) perceived that they do not have requisite knowledge to determine when emptying is due while $44 \%$ believed that they were knowledgeable enough. On the other hand, $60 \%$ of the respondents perceived that they do not have adequate knowledge and understanding of procedures to undertake scheduled emptying of their onsite sanitation systems while $40 \%$ perceived that they had enough knowledge to do so. Nevertheless, $73 \%$ of the respondents perceived that they were confident enough to undertake scheduled emptying while $27 \%$ were less confident. Also, $48 \%$ perceived they would not have the ability to make alternative scheduled emptying plans in the face of challenges such as lack of resources, unavailability of vacuum trucks, etc. Furthermore, $80 \%$ of the respondents perceived that scheduled emptying is important, but only $47 \%$ are willing to put it into practice (Fig. 7). The key informant/group interviews revealed that about $70 \%$ of the participants had a high knowledge level of the negative impacts of faecal sludge overflow from onsite sanitation systems on health and related the prevention measures, but most of them still chose to practice reactive/emergency and unsafe emptying. This is indicative of the fact that knowledge is not enough to change behaviour. 


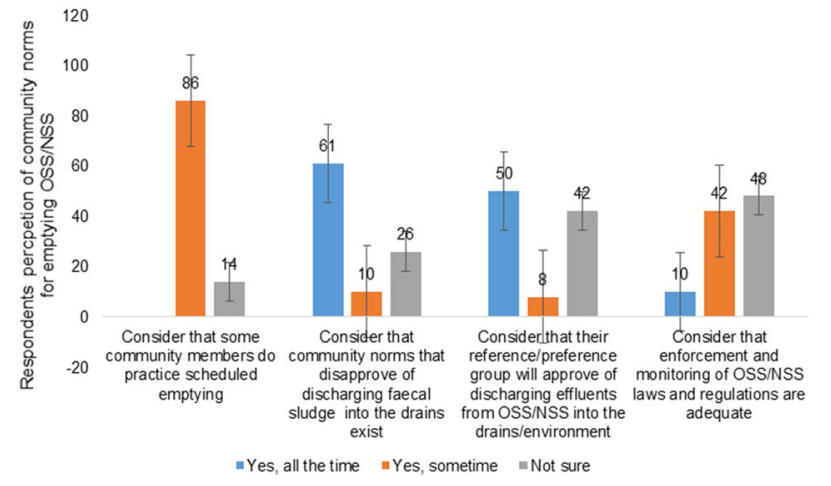

Fig. 6 Respondents' perception of community norms for emptying onsite sanitation systems/non-sewered sanitation systems (OSS/NSS) in the study area. Four-hundred households were surveyed using structured questionnaires to determine prevalent perceptions of the community's' emptying norms for onsite sanitation systems/non-sewered sanitation systems (OSS/NSS) in Khulna Ward 9 community. The respondent's perceived that community members sometimes practiced scheduled (timely and safe) emptying while $14 \%$ were not sure; $6 \%$ agreed that community norms that disapprove of inappropriate faecal sludge discharge exist and adhered to all the time while $10 \%$ believed adherence was only sometimes and $26 \%$ were not sure such norms existed; $50 \%$ of the respondents considered that their reference/preference (i.e., influencers/ peers) groups would disapprove of inappropriate discharge of effluents from OSS/NSS all the time; $8 \%$ believed they would only disapprove sometimes and $42 \%$ were not sure if they would disapprove at all. Only $10 \%$ of them believed that enforcement and monitoring of OSS/NSS laws and regulations were adequate all the time, while $42 \%$ considered them to be adequate sometimes and $48 \%$ were not sure of their adequacy.

Majority of the respondents did not perceive that they had the requisite knowledge for emptying their onsite sanitation systems when due and/or how to undertake scheduled emptying. Moreover, for those who were confident enough to tackle scheduled emptying, there was the consideration that that their ability will be impaired if they were required to make alternative plans in the face of unforeseen challenges (e.g., inaccessibility, damaged infrastructure, flooding etc.). There is also, the effect of income restrictions whereby other priorities causes emptying to be delayed to a later period in spite of perceptions that favour the importance of scheduled emptying. All of these perceptions could also be linked to the community's reactive and unsafe emptying behaviour because when people perceive that they cannot effectively and adequately carry out an action, they are most unlikely to.

\section{Discussion, conclusion and recommendations}

The study of the current onsite sanitation emptying behaviour in Khulna highlights the connection of householders' perceptions with their emptying behaviour. This throws open the question of what is the role of perception in behaviour change through intervention management? Therefore, it becomes imperative that studies are designed to understand the role of perception in sanitation behaviour change. What the current study highlights to some extent is that the perception of respondents greatly determined their emptying behaviour. The emptying behaviour of the surveyed community was evidently, mostly reactive and unsafe such as connecting wastewater from onsite sanitation systems to drainage systems; inaccessible systems for emptying purposes by both the manual and mechanical/motorised operators; over half of the systems never been emptied; about a quarter of them emptied over 3 years ago; emptying only after overflows with backflush into the house; mostly irregular timing and unsafe

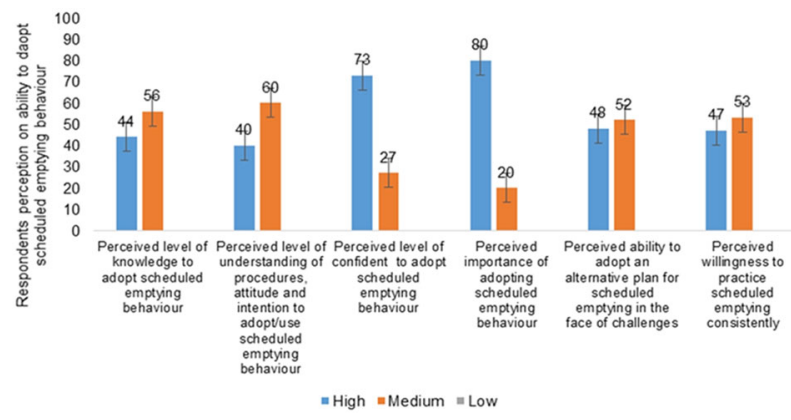

Fig. 7 Respondents' perception on their ability to adopt scheduled emptying (timely and safely) behaviour for onsite sanitation systems/ non-sewered sanitation systems (OSS/NSS) in the study area. Members of 400 households were surveyed via a structured questionnaires on how they perceived their individual and household ability to carried out scheduled emptying (i.e., timely and safely) of onsite sanitation systems/ non-sewered sanitation systems (OSS/NSS) in their community. Perceived level of required knowledge to practice scheduled emptying was high (44\%) and medium (56\%); perceived level of understanding for all requirements was high (40\%) and medium (60\%); perceived level of confidence in own household ability to carry out scheduled emptying was high (73\%) and medium (27\%); perceived importance of scheduled (i.e., timely and safe) emptying behaviour was high (80\%) and medium (20\%); perceived own household ability to adapt alternate plans for scheduled emptying was high (48\%) and medium (52\%); perceived own household willingness to practice scheduled emptying considerably was high (47\%) and medium (53\%); there were no perception of low ability.

emptying with only about one quarter of the systems emptied between the last 6 months- 12 months of the study. These emptying behaviours could be based on certain perceptions of households and the community. So, perceptions that have to do with risks, desired emptying behaviour, norms and ability to empty were extracted from the data to see how they matched with the identified emptying behaviours.

Discussion. Generally, perception of risks and hazards are derived from perceived threats to individual and community wellbeing and the consequences that could accrue from actions and inactions. Threats abound from failing to empty, unsafe and untimely emptying and inappropriate emptying apparatus. The study highlighted situations where manual and mechanical/ motorised emptying methods were hampered due to inaccessibility and sometimes unwillingness/inability to pay. This could be linked to household perceptions of risks and their severity from exposure to faecal sludge and to how those perceptions were formed. Majority of the households did not perceive any negative consequences from systems overflowing with faecal matter and effluents. Households did not perceive any risks to individuals or family members or even the community health. Neither did they consider that there is much risk to public health. These perceptions will definitely affect their attitude to emptying and their intention to perform scheduled emptying. Although, they had enough knowledge to develop the perception that overflowing faecal sludge is inimical to individual and public health, majority of them assumed that the effluent discharge from their neighbours' onsite sanitation systems is more dangerous than the one from their own systems. This creates the 'perception-of-selfexemption' whereby individual households felt they didn't need to empty, but their neighbour does. So, households may know enough to understand the health implications of exposure and contact with faecal sludge, but their perceptions may not produce the required attitudes and intentions to empty and/or empty 

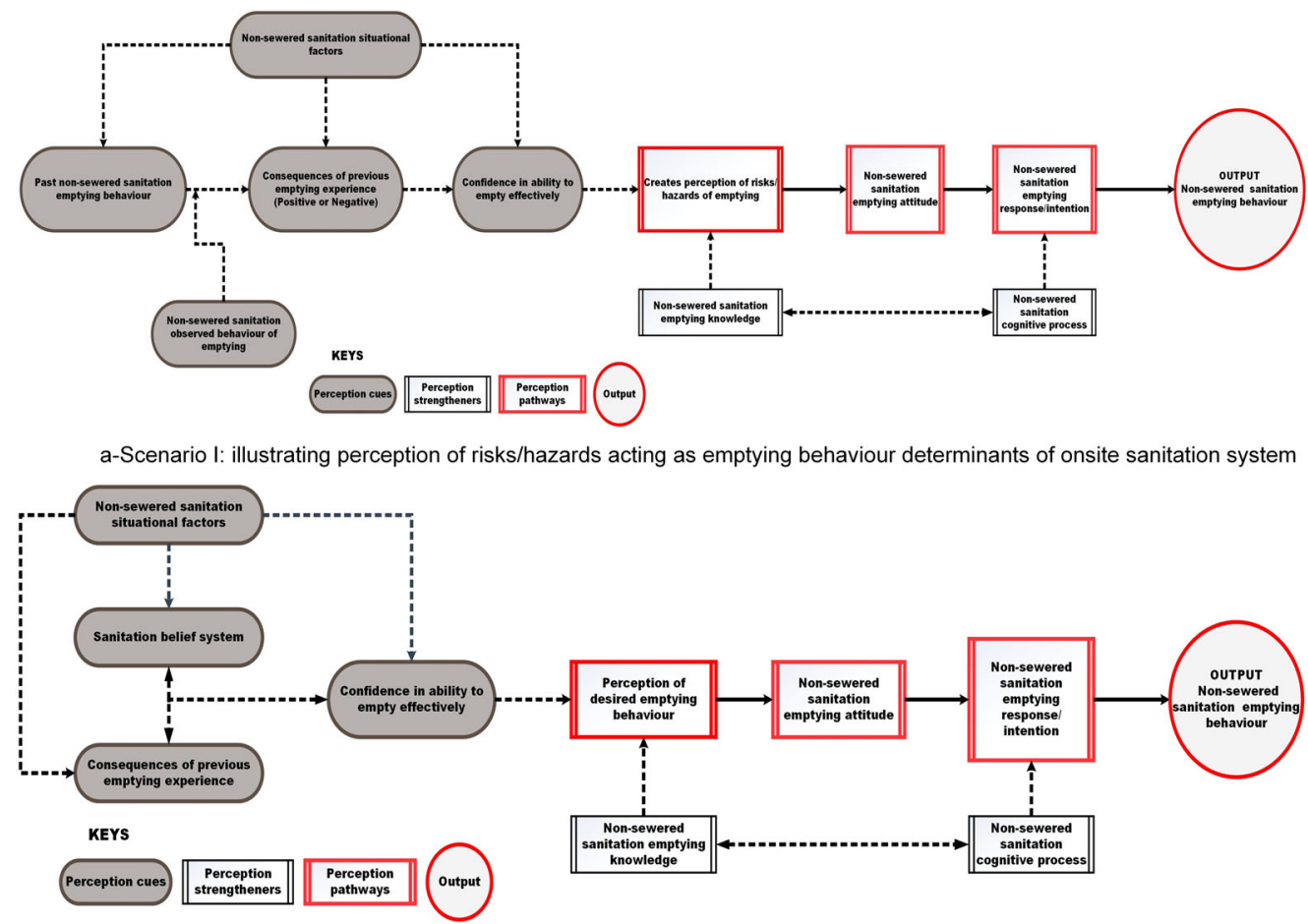

b-Scenario II: illustrating perception of desired emptying acting as behaviour determinants of onsite sanitation system

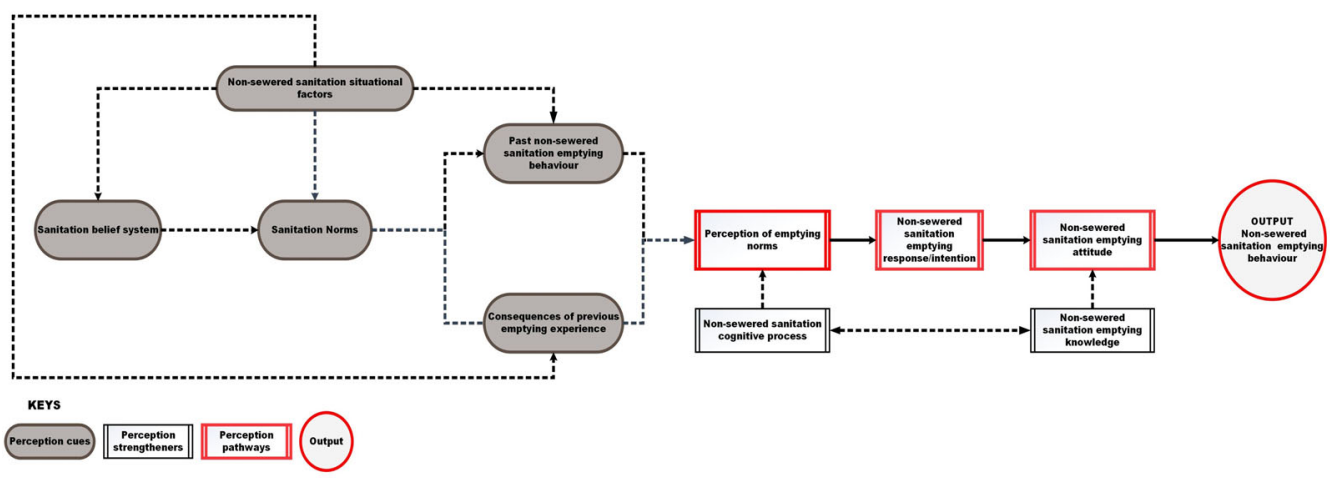

c-Scenario III: illustrating perception of emptying norms acting as emptying behaviour determinants of onsite sanitation system

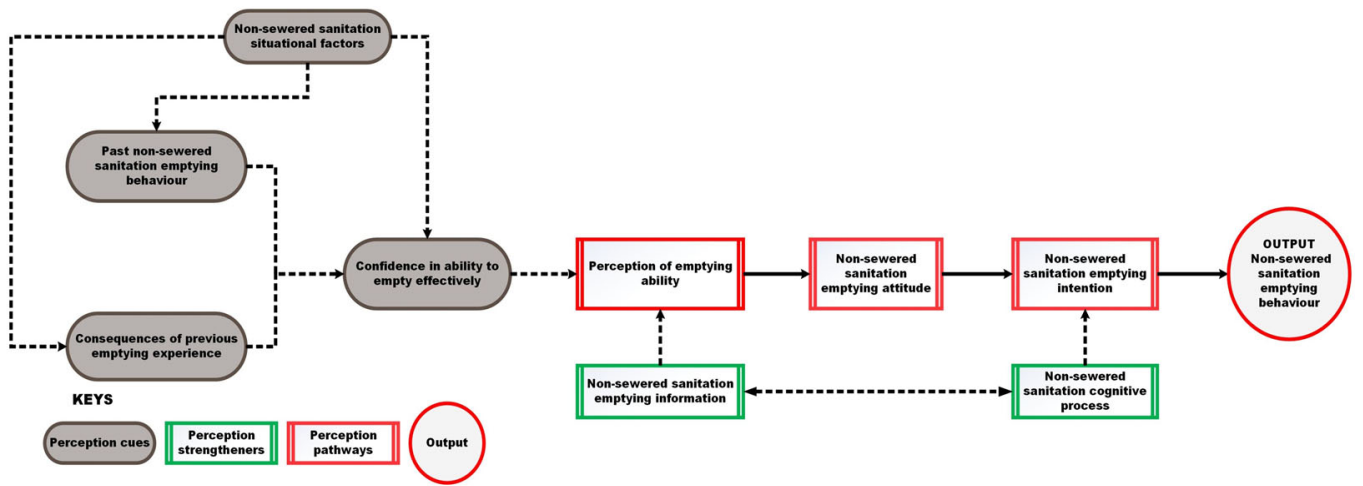

d-Scenario IV: illustrating perception of emptying ability acting as emptying behaviour determinants of onsite sanitation system

appropriately. In other words, perceived susceptibility and vulnerability to the threats of non-emptying or untimely and unsafe emptying and the severity of the consequences did not necessary lead to scheduled emptying.

Furtherance to this, certain past emptying behaviour or observed behaviour (e.g., scheduled, reactive, emptying to drains, etc.) could lead to consequences (positive or negative) that affect individuals' and/or households' confidence in their ability to empty, which then, based on available information and processed knowledge, creates perception of risks and hazards that determine their attitudes and then builds up an intention that is also fed-by information and knowledge to lead to the exhibited emptying behaviour (Fig. 8-Scenario I). This could be one scenario of how perception influences emptying behaviour as evident in the 
Fig. 8 Perception of risks/hazards acting as emptying behaviour determinants, desired emptying acting as behaviour determinants, emptying norms acting as emptying behaviour determinants, and emptying ability acting as emptying behaviour determinants of onsite sanitation systems. a Scenario I: illustrating perception of risks/hazards acting as emptying behaviour determinants of onsite sanitation systems (OSS); b Scenario II: illustrating perception of desired emptying acting as behaviour determinants of onsite sanitation systems (OSS). It is a schematic showing possible cases whereby perception acts as behaviour determinants for onsite sanitation systems/non-sewered sanitation systems (OSS/NSS); c Scenario III: illustrating perception of emptying norms acting as emptying behaviour determinants of onsite sanitation systems (OSS); and d Scenario IV: illustrating perception of emptying ability acting as emptying behaviour determinants of onsite sanitation system. It is a schematic showing possible cases whereby perception act as behaviour determinants for onsite sanitation systems/non-sewered sanitation systems. Perception cues are necessary triggers that could stimulate and prime actual emptying perception; perception straighteners are certain circumstances/conditions that could strengthened emptying perceptions; perception pathways the possible route that perception takes towards corresponding behaviours; the output is the resulting behaviour which in this case, could be timely and safe emptying or unsafe reactive emptying. It shows how certain social and cultural cues lead to certain perceptions that are strengthened by information and cognitive processes that cause related attitudes and intentions to behave in corresponding manner.

respondents' perception of 'no-negative consequences', leading to most households not emptying. Thus, knowledge of health risks and other risks is not enough to produce the desired scheduled emptying behaviour because in the case of Khulna Ward 9, the households were very much aware of the health risks and knew that emptying of onsite sanitation systems is important, but they still did not empty (which could be related to their perception of the connected risks).

Perception of desired emptying behaviour, i.e., to the attitude and the intention of households to actually practice scheduled emptying, is the desired emptying behaviour. This perception could develop from emergencies such as damaged systems, flooding as well as previous experiences, interactions with reference/preference groups, situational factors, etc. but, for most of the Khulna Ward 9 community, the practice of scheduled emptying is perceived as a tiresome and costly activity even though they believed that it would have a positive impact on the community. The addition of faecophobia perceptions whereby elements of disgust with faecal matter leads to avoidance could also be responsible for non-emptying and reactive emptying by majority of the community. Another consideration, could be that even though the belief system encouraged timely and safe emptying, the situational factors of inaccessibility and weak enforcement of relevant laws and regulations designed for the improvement of emptying of onsite sanitation systems affect individual perceptions about scheduled emptying. Another is that a faecophobia belief system will create perceptions that prefer avoidance. For instance, a belief system that views timely and safe emptying as being good for the community, but with a faecophobia background and based on direct consequences of previous emptying behaviour could affect household confidence in their ability for scheduled emptying. This will in turn create a perception about the desired emptying behaviour that could be negative or positive. This perception would be strengthened by information and comprehension of knowledge about scheduled emptying that results in an attitude and intention to perform the desired behaviour (Fig. 8-Scenario II).

Emptying norms are built around communal interactions and belief systems that influence onsite sanitation systems emptying behaviour. Perceptions are derived from these norms to some degree based on their unique and local experiences and these perceptions then guide individual/household behaviour. These norms could also form community perception when widely accepted by the population. Perception of emptying norms are often influenced by social interactions, as well as external and internal social reinforcement in order to change emptying attitudes and intentions. These norms could be derived from home, communities, schools, peers, reference/preference groups, media, etc. These sanitation emptying norms could be faecophobic or faecophilic, household or government responsibility to empty, empty-to-drains, empty when there is visible-sighting of faecal sludge overflow, etc. Meanwhile, perception on enforcement of laws and regulations relevant to ensuring adoption of scheduled emptying were not favourable as most of them considered enforcement to be weak or non-existent. It is, therefore, not surprising that most households discharged faecal sludge directly into the drains, storm-water and environment, and only emptied when there was an overflow. It is evident, then, that belief systems and the sanitation norms are affected by past emptying behaviour and the accruing consequences to create perceptions about existing expectations that affect attitudes and intentions to act (Fig. 8-Scenario III). This suggests that the existing norms did not lead directly to the behaviour, but the perception creates the attitudes and intentions about the norms that determine the behaviour.

Perceived ability and self-efficacy for effective scheduled onsite sanitation emptying may influence the intention and actual practice of the desired behaviour $(49,70)$. This perception is generally influenced by the individual's or household's confidence in their specific capability and other situational factors such as socioeconomic status, physical abilities (or disabilities), location of residence within the city (planned or unplanned), knowledge and information availability, etc. In other words, when residents perceive that they can effectively conduct regular, timely and safe emptying, they would be most likely to sign up for such endeavour. In some cases, situational factors could determine past emptying behaviour and consequences that affect residents' confidence in their ability to simply empty (much more scheduled emptying) and this creates certain information and knowledge that give birth to types of perceptions of households emptying abilities. When these perceptions take hold, they produce attitudes towards emptying and correspondingly follow intentions as to whether or not it is possible or necessary to empty. The final intention will determine the eventual behaviour based on the degree and quality of knowledge and information that comes in at the point of intention (Fig. 8a-d: Scenario I-IV). Generally, the IRF-FSM provisions that require that homeowners or tenants empty their OSS within 6-12 months may be unattainable as most residents seem less inclined towards such arrangements and studies indicates that this may not be the best option (Eales, 2005; Chowdhry and Koné, 2012; Jenkins et al., 2015; Cabıoğlu and İseri, 2015; Prasad and Ray, 2019). Subsequently, the key findings of this paper is that behaviour change interventions cannot be effective without an understanding of the overriding perceptions that lead to current and expected behaviour, and how to manage these perceptions. Thus, to transit communities like Khulna Ward 9 to the desired scheduled emptying behaviour will require in-depth insights into their perceptions of emptying practices and how these perceptions affect their final actions, as well as how to manage them.

Conclusion. Basically, this paper has attempted to show that perception change management is essential to effective sanitation 


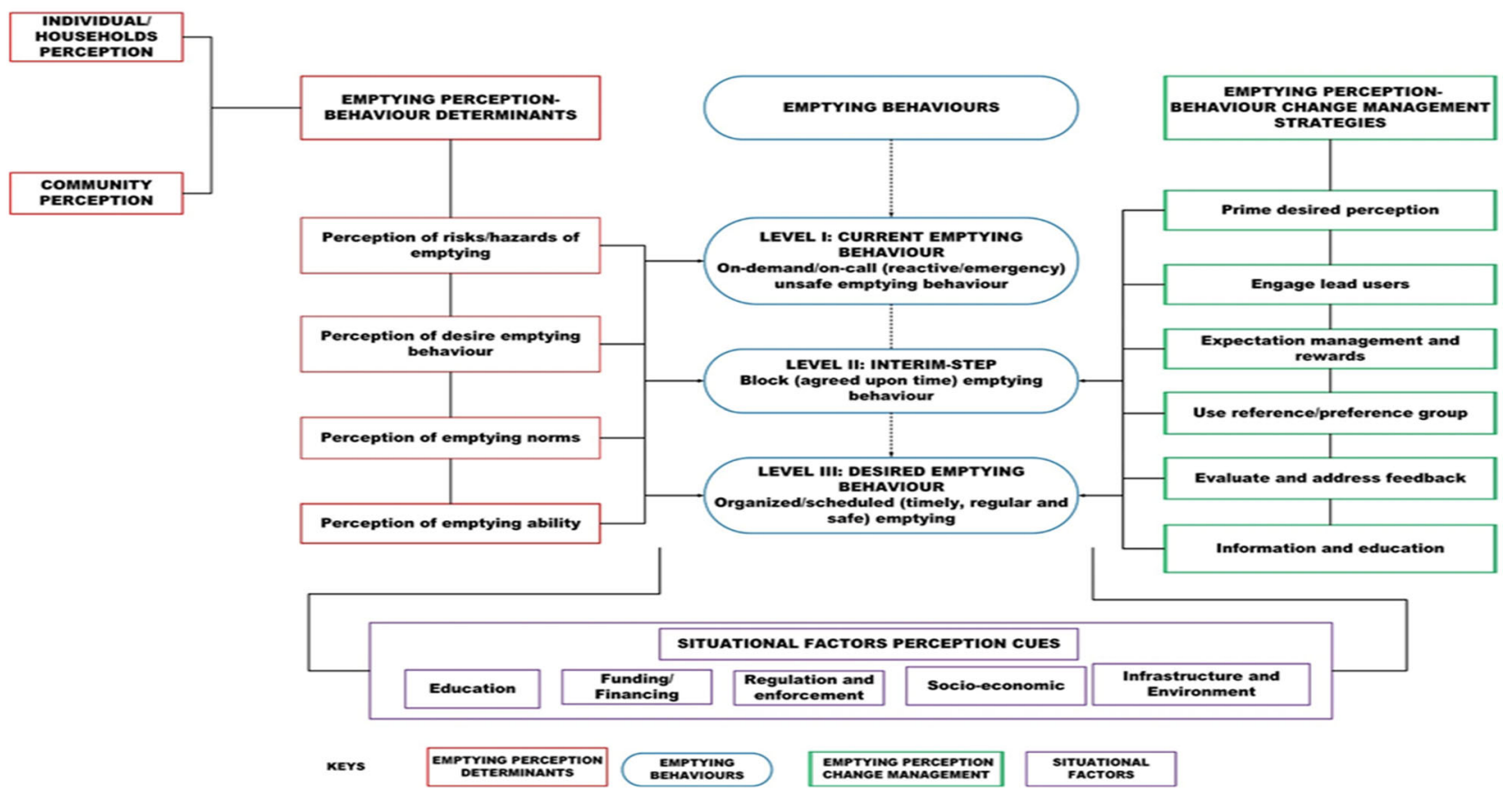

Fig. 9 Emptying perception change management model (EPeCMD) for non-sewered sanitation containment systems towards the achievement of scheduled emptying behaviour. It is a proposed model that shows a pathway for using perception management for behaviour change strategies in onsite sanitation systems/non-sewered sanitation systems (OSS/NSS) interventions.

behaviour change intervention-in this case; scheduled timely and safe emptying of OSS/NSS containment systems. Some scenarios were presented on how certain emptying perceptions could and do affect emptying behaviour. A theoretical consideration showing the linkages between emptying perception cues and actual perceptions and final behaviour was also presented. The next section presents some recommendations and a management model for planning perception change intervention towards behaviour change was proposed. It is imperative that further studies on how perception affects sanitation behaviour are considered so that psycho-social solutions could be used to address unsafe sanitation practices.

Recommendations. It has been suggested that perception management is key to influencing target population to act or behave in a desired form or manner (Ferguson and Bargh, 2004), it is then imperative for sanitation behaviour change proponents to consider the perceptions of their target groups across the sanitation service chain (e.g., emptying) before embarking on intervention programmes. In this paper, a perception change management model (PeCMD) is proposed for behaviour change interventions aimed at scheduled emptying of onsite sanitation systems. The Emptying Perception Change Management Model (EPeCMD) is aimed at influencing individuals', households' and communities' perceptions towards scheduled emptying as behaviour change interventions will be near impossible without appropriate perception management strategies. Thus, this model presents a process in which emptying behaviour can be transformed through perception change management (Fig. 9). First, it is key to note that perception should be targeted at individual, household and community levels and should include factors (e.g., age groups, etc) such as influencers as well as relevant authorities responsible for the governance of the city who are critical stakeholders in ensuring the enabling environment required for emptying practices.
These enabling environments include: (i) ensuring the availability and affordability of scheduled emptying services with ease of access to all strata of the community members; (ii) review and update of relevant legislations, regulations, guidelines and standards that will enhance comprehensive faecal sludge management with particular attention to strengthening scheduled emptying; (iii) strengthening compliance enforcement mechanisms of the relevant arms of the government responsible for the implementation of onsite sanitation emptying services in the community; and (iv) improve onsite sanitation infrastructure and ensure that it complies with the provisions of the relevant codes and regulations.

The emptying perception change management (EPeCMD) model for non-sewered sanitation containment systems is aimed at transforming current unsafe emptying behaviour (Fig. 9). Emptying perception-behaviour determinants (Table 1) are presented on the left of Fig. 9. In the middle are the three levels of emptying behaviour. The first level is the current on-demand, reactive and emergency emptying behaviour, which is unsafe and untimely; the second level is the interim-step, an in-between behaviour designed to reduce the shock of taking the people from level one behaviour straight to level three behaviour, that is organised-scheduled emptying (the desired emptying practice); and on the right are the emptying perception change management strategies (e.g., priming of desired perception, engage lead users, expectation and reward system, use reference/preference group, evaluate and address feedback; and information and education). There are, however, situational factors (e.g., education, funding/financing, regulation and enforcement, socio-economic, infrastructure and environment) that could influence perception while also forming a foundation for perception change management. The onsite sanitation systems' perception change management strategies are series of techniques for controlling and directing perceptions to achieve pre-determined goals that provide needed support mechanisms to transit individuals, households, and communities from on-demand and reactive to 
scheduled emptying behaviour. A brief summary of the emptying perception change management techniques and how they should function is presented below:

I. Priming of desired perceptions to stimulate perceptual activation without conscious guidance or intention to perform the desired emptying behaviour, (Yee and Bailenson, 2009; Mondal et al., 2018) as studies have shown, can change how a person behaves and interacts with other people (Luoma-aho et al., 2019). The activation of the desired perceptual representations is designed to achieve the primed appropriate emptying behaviour traits (Hong et al., 2018);

II. Engaging lead users for early adoption of the desired scheduled emptying behaviour (Rogers, 2015). Early adopters are already integrated into the local community system and have greater degree of opinion leadership in most systems (Rogers, 2003). Therefore, identifying and understanding the characteristics of these individuals and how to involve them can be a critical point to the success of a perception change strategy for a behaviour change intervention programme (Rescorla, 1987);

III. Expectation/reward systems have powerful effects on learning and performance of desired scheduled emptying behaviour because it could provide incentives that change perceptions of the target community (Bresciani et al., 2016; Grant, 2002). Reward and expectation management can take many forms and need to be carefully thought-out (Marteau et al., 2009; Vlaev et al., 2019; DiClemente et al., 2001);

IV. Using reference/preference groups to influence perceptions could create attitudes and intentions to perform the desired emptying behaviour (Tom et al., 1987). This technique requires the identification and use of community groups (external and internal) that most members of the community frequently orient themselves with and to use them to modify emptying perceptions that could create the attitudes and intentions to undertake the desired emptying behaviour (Tom et al., 1987);

V. Evaluating and addressing the feedback of target populations is a technique designed to make agreed solutions more responsive and meet the goals of the perception change programme so as to cause a change in behaviour (Arlinghaus and Johnston, 2017). Feedback techniques whether generic, targeted and/or personalised should provide useful solutions to address all challenges that militated against the adoption of the desired behaviour (Arlinghaus and Johnston, 2017); and

VI. Information and education provides knowledge, facts, and skills that are needed to strengthen the perceptions that create the right attitudes and intentions of households to adopt desired emptying behaviour. It is an initiative that is largely concerned with the process of receiving or giving systematic instructions or as an enlightened experience to facilitate the adoption and reinforcement of scheduled emptying behaviour in a 'target audience' (Bandura, 1977a). Education is required to increase awareness of why it is important to adopt the desired emptying behaviour and to provide training on how to perform the action successfully (Bandura, 1977b). Information and education plays a role in confidence of oneself to adopt the desired behaviour and address the fear of risks, as well as inherent norms that are antithetical to the adoption of scheduled emptying (Bandura, 1977a, 1977b).

To ensure effective and efficient scheduled emptying, perception-behaviour change interventions will have to identify the situational factors and related governance and management issues that may interfere with proposed solutions. Also, appropriate information and education is required for deeper understanding and appreciation of issues around scheduled emptying procedures, processes and technologies and this could also indicate expectations and rewards for the target population's desire to practice the behaviour. Then lead users/early adopters who have already imbibed the new behaviour or some kind of scheduled emptying practice within the community should be identified and engaged. It will also be preferable if these users have some kind of influence within their communities. Furthermore, it is needful to identify reference/preference groups of the target communities whom the residents look-up to and/or emulate so this could transfer the desired emptying behaviour. These could be celebrities, community stars and leaders, teachers, etc. Also, lead users/early adopters and reference/preference groups could be used to prime the perceptions of community members towards scheduled emptying behaviour through community activities, media, and entertainment, etc.; and finally feedback should be adequately and appropriately evaluated and addressed so as to determine the effectiveness of the process and which perceptions should be specifically targeted.

This EPeCMD still needs further investigations to strengthen its potential as the current study was not particularly focused on perception, but served to highlight the role of perception in emptying behaviour. It will require more targeted research in other communities that need to transit from indiscriminate faecal sludge disposal to scheduled timely and safe emptying. There are also some other issues that will need further considerations such as how factors that are deeply rooted in the community (e.g., power relations as it regards gender, age, etc.) affect perceptions and subsequently emptying decisions and choices. In addition, considerations on who should have access to emptying services and at what cost and how these affect emptying perceptions are vital. Meanwhile, a draw-back for EPeCMD will be difficulty of access to adequate, clear and appropriate information and data to make rational and informed decisions as these could affect perceptions. All these indicate that this perception change management model (PeCMD) requires a proper programme mix to address key perception barriers that militate against the adoption of desired behaviours. Also, where apt governance and management approaches that target household and community perceptions are absent or unclear, it could negate the perceptions required to create the attitudes and intentions to perform the desired emptying behaviour.

\section{Data availability}

The data analysed and generated are included in the paper.

Received: 26 June 2020; Accepted: 5 November 2020;

Published online: 16 December 2020

\section{References}

Albarracín D, Wyer RS, Jr. (2000) The cognitive impact of past behavior: Influences on beliefs, attitudes, and future behavioral decisions. J Pers Soc Psychol 79 (1):5-22. https://doi.org/10.1037/0022-3514.79.1.5

Alam MS, Mondal M (2019) Assessment of sanitation service quality in urban slums of Khulna city based on SERVQUAL and AHP model: a case study of railway slum, Khulna, Bangladesh. J Urban Manag 8(1):20-27. https://doi. org/10.1016/j.jum.2018.08.002

Ahmed R, Hassan, S (2012) Hard-to-reach areas: providing water supply and sanitation services to all. supporting poor-inclusive water supply and sanitation sector reforms. Water and Sanitation Program: Guidance Note. http:// documents.worldbank.org/curated/en/374301468208781989/pdf/ 795500REPLACEM00India0Guidance0Note.pdf. Accessed 07 July 2018 
Appiah-Effah E, Nyarko KB, Gyasi SF, Awuah E (2014) Faecal sludge management in low income areas: a case study of three districts in the Ashanti region of Ghana. J Water Sanit Hyg Dev 4(2):189-199. https://doi.org/10.2166/ washdev.2014.126

Armstrong DM (1961) Perception and the physical world. Routledge \& Kegan Paul, London, ISBN: $0710036035196 \mathrm{p}$

Arlinghaus KR, Johnston CA (2017) Advocating for behavior change with education. Am J Lifestyle Med 12(2) 113-116. https://doi.org/10.1177/ 1559827617745479. https://www.ncbi.nlm.nih.gov/pmc/articles/ PMC6124997/pdf/10.1177_1559827617745479.pdf. Accessed 30 Apr 2020

Ajzen I (1985) From intentions to actions: A theory of planned behaviour. In: Kuhl J, Beckman, J (eds) Action-control: From Cognition to Behaviour. Heidelberg, Germany, Springer

Bagheri A, Shabanali Fami H, Rezvanfar A, Asadi A, Yazdani S (2008) Perceptions of paddy farmers towards sustainable agricultural technologies: case of Haraz catchments area in Mazandaran province of Iran. Am J Appl Sci 5 (10):1384e1391. https://doi.org/10.3844/ajassp.2008.1384.1391

Balasubramanya S, Evans B, Ahmed R, Habib A, Asad NSM, Rahman M, Hasan M, Dey D, Camargo-Valero M, Rao KC, Fernando S (2017) Take it away: the need for designing fecal sludge disposal services for single-pit latrines. J Water Sanit Hyg Dev 7(1):121-128. https://doi.org/10.2166/washdev.2017.073

Bandura A (2004) Health promotion by social cognitive means. Health Educ Behav 2004 31:143-164

Bandura A (2000) Health promotion from the perspective of social cognitive theory. In: Norman P, Abraham C, Conner M (eds) In Understanding and changing health behaviour: from health beliefs to self-regulation. Harwood Academic Publishers, Amsterdam, pp. 299-339

Bandura A (1971) Social learning theory. General Learning Press, New York, NY Bandura A (1977a) Social learning theory. Prentice Hall, Englewood Cliffs, NJ

Bandura A (1977b) Self-efficacy: toward a unifying theory of behavioral change. Psychol Rev 84:191-215

Bargh JA, Chen M, Burrows L (1996b) The automaticity of social behavior: direct effects of trait concept and stereotype activation on action. J Pers Soc Psychol $71: 230-244$

Bargh JA, Chartrand T (1999) The unbearable automaticity of being. Am Psychol $54: 462-479$

Bargh JA, Ferguson MJ (2000) Beyond behaviorism: on the automaticity of higher mental processes. Psychol Bull 126:925-945

BBS (Bangladesh Bureau of Statistics), (2015) Census of slum areas and floating population 2014. Preliminary survey report, Statistics and Information Division, Ministry of Planning, Government Peoples' Republic of Bangladesh (2015). http://www.bbs.gov.bd/WebTestApplication/userfiles/Image/Slum/ Preli_Slum_Census.pdf. Accessed 21 Apr 2020

Becker MH (ed) (1974) The health belief model and personal health behavior. Charles B. Slack, Thorofare, NJ

Bernard HR (2002) Research methods in anthropology: qualitative and quantitative methods, 3rd edn. AltaMira Press, Walnut Creek, California

Berkowitz L (1984) Some effects of thoughts on anti- and prosocial influences of media events: a cognitive-neoassociation analysis. Psychol Bull 95:410-427

Bock JK (1986) Syntactic persistence in language production. Cogn Psychol 18:355-387

BNBC (2014) Bangladesh national building code. Ministry of Housing, Bangladesh

Bock JK (1989) Closed-class immanence in sentence production. Cognition 31:163-186. 32

Bornstein MH (2013) Mother-infant attunement: a multilevel approach via body, brain, and behavior. In: Legerstee M, Haley DW, Bornstein, MH (eds.), The infant mind: origins of the social brain. Guilford Press. pp. 266-298

Bresciani C, Colorni A, Lia F, Luè A, Nocerino R (2016) Behavioral change and social innovation through reward: an integrated engagement system for personal mobility, urban logistics and housing efficiency. Transport Res Procedia 14:353-361. https://doi.org/10.1016/j.trpro.2016.05.087

Brewer WF, Lambert BL (2001) The theory-ladenness of observation and the theory-ladenness of the rest of the scientific process. Philos Sci 3:176-18610.1086/392907

Bruner JS (1957) On perceptual readiness. Psychol Rev 64(2):123-152. https://doi. org/10.1037/h0043805

Cabıoğlu MT, İşeri SÖ (2015) Methodological approach in perception management. Open Access Library Journal, 2: e1699. https://doi.org/ 10.4236/oalib.1101699. https://www.researchgate.net/publication/ 282465933_Methodological_Approach_in_Perception_Management. Accessed 29 Apr 2020

Cañal-Bruland R, Van Der Kamp J (2009) Action goals influence action-specific perception. Psychonom Bull Rev 16(6):1100-1105. https://doi.org/10.3758/ PBR.16.6.1100

Cairns-Smith S, Hill H, Nazarenke E (2014) Urban sanitation: why a portfolio is needed; boston consulting group: Boston, MA, USA, 2014. Available online: http://www.bcg.com/documents/file178928.pdf. Accessed on 23 May 2016
Carver CS, Scheier MF (1981) Attention and self-regulation: a control-theory approach to human behavior. SpringerVerlag, New York, NY

Charcot JM (1886) Neue Vorlesungen Uber die Krankhetten des Nervensystems (Autorisierte Deutsche Ausgabe von S. Freud). Toeplitz \& Deuticke, Leipzig, Germany

Chartrand T, Bargh J (1999) The chameleon effect: the perception-behavior link and social interaction. J Pers Soc Psychol 76(6):893-910

Chemero A (2003) Information for perception and information processing. Minds Machines 13:577-588. https://doi.org/10.1023/A:1026209002908.pdf

Chowdhry S, Koné D (2012) Business analysis of fecal sludge management: emptying and transportation services in Africa and Asia-draft final report Bill \& Melinda Gates Foundation, Seattle, USA. https://www.susana.org/ _resources/documents/default/2-1662-chowdhury-2012-business.pdf. Accessed 04 May 2020

Clasen TFBK, Schmidt WP, Boisson S, Fung IC, Jenkins MW, Scott B, Sugden S, and Cairncross $S$ (2010) Interventions to improve disposal of human excreta for preventing diarrhoea. Cochrane Database Syst Rev, CD007180-6.

Cochran WG (1977) Sampling techniques, 3rd edn. Wiley Series in Probability and Statistics, UK, p 448. ISBN: 978-0-471-16240-7

Creswell JW (2009) Research design: qualitative, quantitative and mixed method approaches, 2nd edn. Sage Publications Inc, Thousand Oaks, California

Cookey PE, Darnswasdi R, Ratanachai C (2016) Local people's perceptions of Lake Basin water governance performance in Thailand. Ocean Coast Manag 120:11-28. https://doi.org/10.1016/j.ocecoaman.2015.11.015

Creswell JW, Vicki L, Clark P (2011) Designing and conducting mixed methods research, 2nd edn. Sage, Thousand Oaks, CA, p 201. ISBN: 1412975174

Curtis VA, Danquah LO, Aunger RV (2009) Planned, motivated and habitual hygiene behaviour: an eleven country review. Health Educ Res 24(4):655-673

Curtis V, Schmidt W, Luby S, Florez R, Touré O, Biran A (2011) Hygiene: new hopes, new horizons. Lancet Infect Dis 11(4):312-321

Daniel D, Marks SJ, Pande S, Rietveld L (2018) Socio-environmental drivers of sustainable adoption of household water treatment in developing countries. NPJ Clean Water 1:12. https://doi.org/10.1038/s41545-018-0012-z

Daniel WW, Cross CL (2018) Biostatistics: a foundation for analysis in the health sciences, 11th edn. Wiley Series in Probability and Statistics. Wiley, New York, ISBN: 978-1-119-49657-1

Darnton A (2008) Practical guide: an overview of behaviour change models and their uses. ISBN 978-1-84532-488-9. https://research.fit.edu/media/sitespecific/researchfitedu/coast-climate-adaptation-library/climatecommunications/messaging-climate-change/Darnton.-2008.-BehaviourChange-Models-Uses.pdf. Accessed 24 Apr 2020

Dell GS (1986) A spreading activation theory of retrieval in sentence production. Psychol Rev 93:283-321

Devine J (2010) Beyond tippy-taps: The role of enabling products in scaling up and sustaining handwashing. Waterlines 29(4):304

Devine J (2009) Introducing SaniFOAM: a framework to analyze sanitation behaviors to design effective sanitation programs. The World Bank, Water and Sanitation Program, Washington DC, Working Paper; 22

DiClemente CC, Marinilli AS, Singh M, Bellino LE (2001) Am J Health Behav 25 (3):217-27. https://doi.org/10.5993/AJHB.25.3.8. https://www.researchgate.net/ publication/12012814_The_Role_of_Feedback_in_the_Process_of_Health_ Behavior_Change. Accessed 30 Apr 2020

Dijksterhuis A, van Knippenberg A (1998) The relation between perception and behavior, or how to win a game of Trivial Pursuit. J Pers Soc Psychol 74 (4):865-877. https://doi.org/10.1037/0022-3514.74.4.865

Dodane PH, Mbeguere M, Sow O, Strande L (2012) Capital and operating costs of full-scale fecal sludge management and wastewater treatment systems in Dakar, Senegal. Environ Sci Technol 46:3705-3711

Dreibelbis R, Winch PJ, Leontsini E, Hulland KRS, Ram PK, Unicomb L, Luby SP (2013) The integrated behavioural model for water, sanitation, and hygiene: a systematic review of behavioural models and a framework for designing and evaluating behaviour change interventions in infrastructure-restricted settings. BMC Public Health 13. https://doi.org/10.1186/1471-2458-13-1015

Eagly AH, Chaiken S (1993) The psychology of attitudes. Harcourt Brace, San Diego, CA

Eales K (2005) Bringing pit emptying out of the darkness: a comparison of approaches in Durban, South Africa, and Kibera, Kenya. Sanitation Partnerships Series. https://www.ircwash.org/sites/default/files/Eales-2005-Bringing. pdf. Accessed 03 May 2020

Eawag/Sandec (2015) SFD Report Khulna, Bangladesh. https://www.eawag.ch/ fileadmin/Domain1/Abteilungen/sandec/publikationen/EWM/SFD/ SFD_Sandec_Khulna.pdf. Accessed 21 Apr 2020

EHP, UNICEF/WES, USAID, World Bank/WSP, and WSSCC (2004) The hygiene improvement framework: a comprehensive approach for preventing childhood diarrhea. Environmental Health Project, Washington, DC

Eidelberg L (1929) Experimenteller Beitrag zum Mechanismus der Imitationsbewegung. Jahresbucher fur Psychiatric und Neurologic 46:170-173 
Etikan I, Musa SA, Alkassim RS (2016) Comparison of convenience sampling and purposive sampling. J Am J Theor Appl Stat 5:1-4. https://doi.org/10.11648/j. ajtas.20160501.11

Ferguson MJ, Bargh JA (2004) How social perception can automatically influence behaviour. Trend Cognit Sci 8(1):33-39. https://doi.org/10.1016/j. tics.2003.11.004

Figueroa ME, Kincaid DL (2010) Social, cultural, and behavioral correlates of household water treatment and storage. In Center Publication HCI 2010-1: Health Communication Insights. Johns Hopkins Bloomberg School of Public Health, Center for Communication Programs, Baltimore. http://ccp.jhu.edu/ wp-content/uploads/Household-Water-Treatment-and-Storage-2010.pdf. Accessed 03 May 2020

Fishbein M, Ajzen I (1975) Belief, attitude, intention, and behavior: an introduction to theory and research. Addison-Wesley, Reading, MA

Firestone C, Scholl BJ (2015) Can you experience top-down effects on perception? The case of race categories and perceived lightness. Psychon Bull Rev 22:694-700

Fodor JA (1983) The modularity of mind: an essay in faculty psychology. MIT Press, Cambridge

Funk DC, James J (2001) The psychological continuum model: a conceptual framework for understanding an individual's psychological connection to sport. Sport Manag Rev 4:119-150

Funk DC, James J (2006) The meaning of consumer loyalty: the role of attachment in the developmental progression from attraction to sport team allegiance. J Sport Manag 20:189-217

Fuster JM, Bressler SL (2015) Past makes future: role of $\mathrm{pFC}$ in prediction. J Cogn Neurosci 27(4):639-54. https://doi.org/10.1162/jocn_a_00746. Epub 2014 Oct 16

Gill L, Mahon JM, Knappe J, Gharbia S, Pilla F (2016) Desludging rates and mechanisms for domestic wastewater treatment system sludges in Ireland. Environmental Protection Agency, Wexford, http://www.epa.ie/pubs/reports/ research/water/Research_Report_253.pdf. Accessed 03 May 2020

Grant R (2002) The ethics of incentives: historical origins and contemporary understandings. Econ Philos 18:111-39

Grizzell J (2007) Behavior change theories and models. https://www.cpp.edu/ $\sim$ jvgrizzell/best_practices/bctheory.html. Accessed 24 April 2020

Gollwitzer PM, Sheeran P (2006) Implementation intentions and goal achievement: a metaanalysis of effects and processes. Adv Exp Soc Psychol 38:249-268

Harper J, Bielefeldt A, Javernick-Will A, Veasna T (2018) Intentions toward fecal sludge management in rural developing communities. Paper presented at Engineering Project Organization Conference: Brijuni, Croatia https:// www.researchgate.net/publication/326607793_Intentions_Toward_ Fecal_Sludge_Management_in_Rural_Developing_Communities. Accessed on 17 Oct 2018

Hashimoto K (2019) Institutional mechanisms for sustainable sanitation: lessons from Japan for other Asian Countries. ADBI Working Paper 1001. Asian Development Bank Institute, Tokyo

Hochbaum G (1958) Public participation in medical screening programs: a sociopsychological study. (Public Health Service Publication No. 572). Government Printing Office, Washington, D.C.

Hollingworth C, Barker L (2017) How to use behavioural science to build new habits. Source: WARC Best Practice, June 2017. https://www.thebearchitects. com/assets/uploads/TBA_Warc_How_to_use_behavioural_science_to_build_ habits.pdf. Accessed 19 Apr 2020

Hong C, Lin M, Sun P, Yang H (2018) Framework of early adopters' incipient and innovative ideas and chance discovery. J Inf Telecommun 2(1):19-32. https:// doi.org/10.1080/24751839.2017.1359754

ISF-UTS and SNV (2019) Scheduled emptying services as an entry point for change. SNV, The Hague, https://snv.org/cms/sites/default/files/explore/ download/2019-scheduled-emptying-services-entrypoint-change-ushhdpaper_0.pdf. Accessed 21 Apr 2020

Islam S (2016) "Study on faecal sludge management in three municipalities of Bangladesh." M.Sc Thesis. Khulna University of Engineering and Technology (KUET), Bangladesh

James W (1890) Principles of psychology. Henry Holt

Jenkins MW, Cumming O, Cairncross S (2015) Pit latrine emptying behavior and demand for sanitation services in Dar Es Salaam, Tanzania. Int J Environ Res Public Health 12:2588-2611

Jenkins MW, Scott B (2007) Behavioral indicators of household decision-making and demand for sanitation and potential gains from social marketing in Ghana. Soc Sci Med 64(12):2427-2442

Jordaan W, Jordaan J (1989) Man in context, 2nd edn. Lexicon, Isando, Johannesburg

Kabir A, Salahuddin, M (2014) A baseline study to assess faecal sludge management of residential premises in selected southern cities of Bangladesh. https://snv. $\mathrm{org} / \mathrm{cms} / \mathrm{sites} /$ default/files/explore/download/snv___baseline_study_to_ assess_fsm_of_residential_premises.pdf. Accessed 20 Apr 2020
Kengne IM, Soh Kengne E, Amougou AK, Bemmo N, Dodane P-H, Koné D (2011) Vertical-flow constructed wetlands as an emerging solution for faecal sludge dewatering in developing countries. J Water Sanitation Hyg Dev 1(1):13-19

Kirsch K, Hammersley-Mather, R, (2017) After the pit is full: understanding latrine emptying in Fort Dauphin, Madagascar. Loughborough University. Conference contribution. https://hdl.handle.net/2134/31493. https://repository lboro.ac.uk/articles/After_the_pit_is_full_understanding_latrine_emptying_ in_Fort_Dauphin_Madagascar/9589286. Accessed 02 May 2020

Koffka K (1925) Die Grundlagen der psychischen Entwicklung. Osterwieck, Germany, Zickfeldt

Koottatep T, Cookey PE, Polprasert C (2019) Regenerative sanitation: a framework for sanitation 4.0. IWA Publishing, the Hague, Netherlands, https://www. iwapublishing.com/books/9781780409672/regenerative-sanitation-newparadigm-sanitation-40. Accessed 19 Apr 2020. ISBN13: 9781780409672

Kugedera Z (2019) Determinants of timely and safe on-site sanitation systems desludging in Khulna, Bangladesh. Master of Science in Sanitation Thesis carried out in partial fulfilment of requirements for the Master of Science degree at the UN-IHE Institute for Water Education, Delft, the Netherlands. https://www.researchgate.net/project/Determinants-of-timely-and-safe-onsite-sanitation-systems-desludging-in-Khulna-Bangladesh. Accessed 21 Apr 2020

Lewis A (2001) The issue of perception: some educational implications. Corpus ID: 51734891. https://pdfs.semanticscholar.org/8b13/d8fad80dccf749908005c537c9a6 10cd1673.pdf?_ga $=2.90062811 .1778975802 .1588437466-296416183.1583163380$ Accessed 02 May 2020

Liska AE (1984) A critical examination of the causal structure of Fishbein/Ajzen attitude-behavior model. Soc Psychol Quart 47:61-74

Loritoa CD, Pollock K, Harwood R, das Nair R, Logan P, Goldberg S, Booth V, Vedhara K, Van Der Wardt V (2019) A scoping review of behaviour change theories in adults without dementia to adapt and develop the 'PHYT in dementia', a model promoting physical activity in people with dementia. Maturitas 121:101-113. https://doi.org/10.1016/j.maturitas.2019.01.008

Luoma-aho V, Pirttimäki T, Maity D, Munnukka J, Reinikainen H (2019) Primed authenticity: how priming impacts authenticity perception of social media influencers. Int J Strateg Commun 13(4):352-365. https://doi.org/10.1080/ 1553118X.2019.1617716

Marteau TM, Ashcroft RE, Oliver A (2009) Using financial incentives to achieve healthy behavior. BMJ 338:b1415

Mara D (1996) Low-cost urban sanitation. John Wiley, Chichester, p240, https:// www.wiley.com/en-us/Low+Cost+Urban+Sanitation-p-9780471961635 ISBN: 978-0-471-96163-5. Accessed 22 Apr 2020

Mansour G, Islam W, Akhtaruzzaman, M (2017) Situation analysis of the urban sanitation sector in Bangladesh. Water \& Sanitation for the Urban Poor. https://www.wsup.com/content/uploads/2017/09/Situation-analysis-of-theurban-sanitation-sector-in-Bangladesh.pdf. Accessed 21 Apr 2020

Mehta M, Mehta D, Yadav U (2019) Citywide inclusive sanitation through scheduled desludging services: emerging experience from India. Front Environ Sci https://doi.org/10.3389/fenvs.2019.00188

Mischel W (1973) Toward a cognitive social learning reconceptualization of personality. Psychol Rev 80:252-283

Michel A (2019) Cognition and perception: is there really a distinction? This article is based in part on an Integrative Science Symposium at the 2019 International Convention of Psychological Science (ICPS) in Paris. Learn about ICPS 2021 in Brussels. https://www.psychologicalscience.org/observer/cognitionand-perception-is-there-really-a-distinction. Accessed 20 Apr 2020

Mills F (2013) Assessment of sludge accumulation and pit filling rates in indonesia. WSP of the World Bank, East Asia

Mills F, Blackett IC, Tayler K, (2019) Assessing on-site systems and sludge accumulation rates to understand pit emptying in Indonesia. figshare. https://hdl. handle.net/2134/31078. https://repository.lboro.ac.uk/articles/Assessing_onsite_systems_and_sludge_accumulation_rates_to_understand_pit_emptying_in_Indonesia/9595880. Accessed 03 May 2020

MoLGRD\&C (Ministry of Local Government Rural Development and Cooperatives) (2017) Institutional and Regulatory Framework for Faecal Sludge Management (IRF-FSM). Government of the People's Republic of Bangladesh. https://ocw.un-ihe.org/pluginfile.php/4172/mod_resource/content/1/ FSM\%20Framework-Mega\%20City\%20Dhaka.pdf. Accessed 22 Apr 2020

Montangero A (2004) Material flow analysis as a tool for environmental sanitation planning in developing countries. NCCR North-South Ph.D. thesis proposal to EAWAG/SANDEC, Zurich. https://www.dora.lib4ri.ch/eawag/islandora/ object/eawag\%3A12497/datastream/PDF/Montangero-2006-

Material_flow_analysis_for_environmental-\%28published_version\%29.pdf Accessed 22 Apr 2020

Mosler HJ (2012) A systematic approach to behavior change interventions for the water and sanitation sector in developing countries: a conceptual model, a review, and a guideline. Int J Environ Health Res 22:431-449. https://doi.org/ $10.1080 / 09603123.2011 .650156$ 
Mondal S, Moniruzzaman S, Islam MS (2018) Study on emptying of faecal sludge at selected areas in Khulna City. J Eng Sc 9(1):77-84. https://www2.kuet.ac. bd/JES/images/files/v91/9_JES_165.pdf ISSN 2075-4914. Accessed 22 Apr 2020

Mondal S (2018) Faecal sludge management in Khulna City: an approach for safe emptying. a master of science thesis in civil engineering, Department of Civil Engineering, Khulna University of Engineering \& Technology, Khulna, Bangladesh. http://dspace.kuet.ac.bd/bitstream/handle/20.500.12228/96/Full $\% 20$ Thesis.pdf?sequence $=1$ \&isAllowed $=$ y. Accessed 21 Apr 2020

Morris J, Marzano M, Dandy N, O'Brien L (2012) Forest research: forestry, sustainable behaviours and behaviour change: Theories and models of behaviour and behaviour change. https://www.changewildlifeconsumers.org/site/assets/ files/1369/behaviour_review_theory.pdf. Accessed 24 Apr 2020

Munro S, Lewin SA, Swart T, Volmink J (2007) A review of health behaviour theories: how useful are these for developing interventions to promote longterm medication adherence for TB and HIV/AIDS? BMC Public Health 7:104. https://doi.org/10.1186/1471-2458-7-104

Mulder G (1979) Perception as information processing. Urban Ecol 4:103-118

Murungi C, Pieter van Dijk M (2014) Emptying, transportation and disposal of feacal sludge in informal settlements of Kampala Uganda: the economics of sanitation. Habit Internat 42:69-75. https://doi.org/10.1016/j.habitatint.2013.10.011

Nakagiri A, Niwagaba CB, Nyenje PM, Kulabako RN, Tumuhairwe JB, Kansiime F (2016) Are pit latrines in urban areas of Sub-Saharan Africa performing? A review of usage, filling, insects and odour nuisances. BMC Public Health 16:120. https://doi.org/10.1186/s12889-016-2772-z. 2015

Navarro RG (1994) Improving sanitation in coastal communities with special reference to Puerto Princesa, Palawan Province, Philippines. PhD thesis, McGill University, Montreal, Canada. http://www.bvsde.paho.org/texcom/ cd050999/navarro.pdf. Accessed 07 Aug 2018

Neil SC, Melanie AF, Helen H, Eithne H (2016) Applying theories of health behaviour and change to hearing health research: Time for a new approach. Int J Audiol 55 (sup3):S99-S104. https://doi.org/10.3109/14992027.2016.1161851

Novotny E, Carr Z, Frank MG, Dietrich SB, Shaddock T, Cardwell M, Decker A (2018) How People Really Suspect and Discover Lies. J Nonverbal Behav 42:41-52. https://doi.org/10.1007/s10919-017-0263-2

Opel A 2012 Absence of faecal sludge management shatters the gains of improved sanitation sanitation coverage in Bangladesh. Sustainable sanitation practise. https://www.ircwash.org/resources/absence-faecal-sludge-managementshatters-gains-improved-sanitation-coverage-bangladesh. Accessed $21 \mathrm{Apr}$ 2020

Opel A, Bashar MK, Ahmed MF (2012). Faecal sludge management in Bangladesh: an issues that needs urgent attention. Asia regional sanitation and hygiene practitioners workshop. https://www.susana.org/_resources/documents/ default/2-1674-opel-fsm.pdf. Accessed 21 Apr 2020

Park CW, Gardner MP, Thukral VK (1988) Self-perceived knowledge: some effects on information processing for a choice task. Am J Psychol, 101(3) 401-424, https://www.jstor.org/stable/1423087. Accessed 20 Apr 2020

Parkinson J, Quader M (2008) The challenge of servicing on-site sanitation in dense urban areas: experiences from a pilot project in Dhaka. Waterlines 27(2) 149-163. https://www.jstor.org/stable/pdf/24685044.pdf?refreqid=excelsior\% 3Ae9e6ca649c4f91eac92b4668558f40a7. Accessed 04 May 2020

Peal A, Evans B, Blackett I, Hawkins P, Heymans C (2014) Fecal sludge management: a comparative assessment of 12 cities. J Water Sanit Hyg Dev 4 (4):563-575

Piaget J (1946) La information du symbole chez Venfant. Delachaux \& Niestle, Paris

Prasad CSS, Ray I (2019) When the pits fill up: (in)visible flows of waste in urban India. J Water Sanit Hyg Dev 9(2):338-347. https://doi.org/10.2166/ washdev.2019.153

Prinz W (1990) A common coding approach to perception and action. In: Neumann O, Prinz W (eds.) Relationships between perception and action. Springer-Verlag, Berlin, Germany, pp. 167-201

Rainey RC, Harding AK (2005) Acceptability of solar disinfection of drinking water treatment in Kathmandu Valley, Nepal. Int J Environ Health Res 15 (5):361-372

Repon AC, Faruq O, Mamtaz R (2015) Occupational safety and health guidelines for faecal sludge management. SNV Netherlands Development Organisation, Netherlands

Rescorla RA (1987) A Pavlovian analysis of goal-directed behavior. Am Psychol 42 (2):119-129

Rogers EM (2015) Evolution: diffusion of innovations. In: International Encyclopedia of the Social \& Behavioral Sciences (2nd edn). https://doi.org/10.1016/ B978-0-08-097086-8.81064-8. https://www.sciencedirect.com/science/article/ pii/B9780080970868810648. Accessed 30 Apr 2020

Rogers EM (2003) Diffusion of innovations. Free Press, New York, NY

Rosenstock IM (1966) Why people use health services. Milbank Quart 44:94-124

Rosenquist LED (2005) A psychosocial analysis of the human-sanitation nexus. J Environ Psychol 25:335-346. https://doi.org/10.1016/j.jenvp.2005.07.003
Ross I, Scott R, Ravikumar J (2016a) Fecal sludge management: diagnostics for service delivery in urban areas. WSP, World Bank Group, Washington DC, USA

Ross I, Scott RE, Xavier, JR (2016b) Fecal sludge management: diagnostics for service delivery in urban areas-case study in Dhaka, Bangladesh

Roy TK (2014) Sustainable options of sanitation projects in the slums of Khulna City. Equality in the city: making cities socially cohesive, world town planning day 2014. https://www.bip.org.bd/SharingFiles/journal_book/ 20141118150912.pdf. Accessed 21 Apr 2020

Saxena DP (1971) The "Reference Group" concept. Soc Sci 46(3):155-164

Sharma M, Romas JA (2012) Theoretical foundations of health education and health promotion. Jones and Bartlett Learning, London

Schank RC, Abelson RP (1977) Scripts, plans, goals, and understanding. Erlbaum, Hillsdale, NJ

Scherer KR, Walbott HG (1994) Evidence for universality and cultural variation of differential emotion response patterning. J Pers Soc Psychol 66:310-328

Schoebitz L, Bischoff F, Lohri CR, Niwagaba CB, Siber R, Strande L (2017) GIS analysis and optimisation of faecal sludge logistics at city-wide scale in Kampala, Uganda. Sustainability 9:194. https://doi.org/10.3390/su9020194

Schwarzer R (2008) Modeling health behavior change: how to predict and modify the adoption and maintenance of health behaviors. Appl Psychol: Int Rev 57 (1):1-29

Seimetz E, Boyayo A, Mosler H (2016) The influence of contextual and psychosocial factors on handwashing. Am J Trop Med Hyg, 94(6), 1407-1417. https://doi.org/ 10.4269/ajtmh.15-0657. http://www.ajtmh.org/docserver/fulltext/14761645/94/6/ 1407.pdf?expires $=1588557371 \&$ id $=$ id\&accname $=$ guest\&checksum $=$ DB49 C25188AA6E73C77BD295B523A644. Accessed 04 May 2020

Skinner BF (1953) Science and human behavior. Macmillan, New York, NY

Strande L, Schoebitz L, Bischoff F, Ddiba D, Okello F, Englund M, Warda BJ, Niwagaba CB (2018) Methods to reliably estimate faecal sludge quantities and qualities for the design of treatment technologies and management solutions. J Environ Manag 223:898-907. https://doi.org/10.1016/j.jenvman.2018.06.100

Strande L, Ronteltap M, Brdjanovic D (2014) Faecal sludge management-systems approach for implementation and operation. IWA Publishing, London, UK

Strauss M, Montangero A, (2002) "FS management: review of practices, problems, and initiatives." London and Duebendorf, DFID Project. https://www. ircwash.org/sites/default/files/Strauss-2002-FS.pdf. Accessed 22 Apr 2020

SNV (2014) A baseline study to assess Faecal sludge management of residential premises in selected southern cities of Bangladesh. https://snv.org/cms/sites/ default/files/explore/download/snv _ baseline_study to assess_fsm_of residential_premises.pdf. Accessed 21 Apr 2020

Sudman S, Bradburn N (2004) Asking questions: the definitive guide to questionnaire design-for market research, political polls, and social and health questionnaires, 2nd, revised edn. Jossey Bass, San Francisco, ISBN: 978-0787-97088-8

Sydhagen PB (2017) How can we distinguish perception from cognition? the perceptual adaptation hypothesis. Thesis presented for the degree of Master of Philosophy. Department of Philosophy, Classics, History of Art and Ideas University of Oslo. https://www.duo.uio.no/bitstream/handle/10852/58422/ Sydhagen.pdf?sequence $=1$ \&isAllowed $=y$. Accessed 20 Apr 2020

Tacca MC (2011) Commonalities between perception and cognition. Front Psychol 2:358. https://doi.org/10.3389/fpsyg.2011.00358. https://www.ncbi.nlm.nih. gov/pmc/articles/PMC3227022/. Accessed 20 Apr 2020

Tankard ME, Paluck EL (2016) Norm perception as a vehicle for social change. Soc Issues Policy Rev 10(1):181-211. https://staticl.squarespace.com/static/ 5186d08fe4b065e39b45b91e/t/568de2f4e0327c7b8a288d06/1452139252477/ TankardPaluck+2016.pdf. Accessed 19 Apr 2020

Tasaduzzaman S (2015) Public service provider, Conservancy Department. In Gunawan A (ed.) In SFD Promotion Initaitives, Khulna, Bangladesh, Final Report 2015. Published by Eawag/Sandec, Switzerland.

Taylor SE (1975) On inferring one's attitudes from one's behavior: Some delimiting conditions. J Pers Soc Psychol 31:126-131

Thye YP, Templeton MR, Ali M (2011) A critical review of technologies for pit latrine emptying in developing countries. Environ Sci Technol 41:1793-1819

Tom G, Barnett T, Lew W, Selmants J (1987) "Cueing the consumer: the role of salient cues in consumer perception”. J Consum Mark 4(2):23-27. https://doi org/10.1108/eb008193

Tongco DC (2007) Purposive sampling as a tool for informant selection. Ethnobot Res Appl 5:147-158. http://journals.sfu.ca/era/index.php/era/article/viewFile/ 126/111. Accessed 22 Apr 2020

Tyagi AJ (2017) Predicament of sanitation workers in Swachh Bharat. Tehelka Magazine. http://www.tehelka.com/2017/10/predicament-of-sanitationworkers-in-swachh-bharat/. Accessed 10 Apr 2018

USAID (United States Agency for International Development) (2010) A rapid assessment of septage management in Asia. USAID, Washington, DC

Vallacher RR (1993) Mental calibration: forging a working relationship between mind and action. In: Wegner DM, Pennebaker JW (eds.) Handbook of mental control. Prentice Hall, Englewood Cliffs, NJ, pp. 443-472 
Van Vliet BJM, Spaargaren G, Oosterveer P (2011) Sanitation under challenge: contributions from the social sciences. Water Policy 13:797-809

Yee N, Bailenson JN (2009) The difference between being and seeing: the relative contribution of self-perception and priming to behavioral changes via digital self-representation. Media Psychol 12(2):195-209. https://doi.org/10.1080/ 15213260902849943

Vlaev I, King D, Darzi A, Dolan P, (2019) Changing health behaviors using financial incentives: a review from behavioral economics. BMC Public Health 19:1059 https://doi.org/10.1186/s12889-019-7407-8. https://bmcpublichealth.biomed central.com/track/pdf/10.1186/s12889-019-7407-8. Accessed 30 Apr 2020

WHO and UNICEF (2017) Progress on drinking water, sanitation and hygiene: update and SDG Baselines. World Health Organization (WHO) and the United Nations Children's Fund (UNICEF), Geneva, http://www.who.int/mediacentre/news/ releases/2017/launch-version-report-jmp-water-sanitation-hygiene.pdf?ua $=1$. Accessed 5 Oct 2017

Wicker AW (1969) Attitudes versus actions: the relationship of verbal and overt behavioral responses to attitude objects. J Soc Issue 25(4 Feb):41-78

Wikipedia contributors (2020) Khulna. In Wikipedia, The Free Encyclopedia. Retrieved 08:43, 12 May 2020, from https://en.wikipedia.org/w/index.php? title $=$ Khulna\&oldid $=955563580$. Accessed 12 May 2020

Wood S, Foster J, Kols A (2012) Understanding why women adopt and sustain home water treatment: insights from the Malawi antenatal care program. Soc Sci Med 75(4):634-642

Yin RK (2003) Case study research: design and methods, 5th edn. Sage Publications, Thousand Oaks

\section{Acknowledgements}

Our sincere appreciation goes to SNV Khulna, Bangladesh for their guidance during the field work. In addition, we are grateful to all households, community leaders and KCC officers who participated in the field survey. We also appreciate Khulna University of Engineering and Technology (KUET), Khulna, Bangladesh for helping with the field work. I also, want to acknowledge the assistance of Mrs Mayowa Peter-Cookey for proof reading the entire manuscript. This research study was funded by Bill and Melinda Gates Foundation (BMGF) through the Water, Sanitation and Hygiene programme to train a generation of sanitation professionals who will help create a world where children and families lead healthier, more productive lives. BMGF did not participate in the study design, data collection, analysis and interpretation and writing of the manuscript.

\section{Author contributions}

PEC mentored and guided all phases of ZK's MSc Sanitation thesis' research from design, data collection, analysed data and thesis report under the broader study title 'Determinants of timely and safe on-site sanitation systems desludging in Khulna, Bangladesh. MA was the field supervisor of ZK while in Khulna during the field work. DB was the Professor of the Sanitary Engineering Chair Group, reviewed the article and gave the final approval for this publication. PEC wrote this paper. All authors read and approved the final manuscript.

\section{Competing interests}

The authors declare no competing interests.

\section{Additional information}

Correspondence and requests for materials should be addressed to P.E.C.

Reprints and permission information is available at http://www.nature.com/reprints

Publisher's note Springer Nature remains neutral with regard to jurisdictional claims in published maps and institutional affiliations.

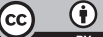

Open Access This article is licensed under a Creative Commons Attribution 4.0 International License, which permits use, sharing, adaptation, distribution and reproduction in any medium or format, as long as you give appropriate credit to the original author(s) and the source, provide a link to the Creative Commons license, and indicate if changes were made. The images or other third party material in this article are included in the article's Creative Commons license, unless indicated otherwise in a credit line to the material. If material is not included in the article's Creative Commons license and your intended use is not permitted by statutory regulation or exceeds the permitted use, you will need to obtain permission directly from the copyright holder. To view a copy of this license, visit http://creativecommons.org/ licenses/by/4.0/.

(C) The Author(s) 2020 